\title{
SUICIDIO ASISTIDO Y LIBRE DESARROLLO DE LA PERSONALIDAD EN LA REPÚBLICA FEDERAL DE ALEMANIA
}

PABLO RIQUELME VÁZQUEZ 


\section{SUMARIO:}

\section{LA PROHIBICIÓN DEL FAVORECIMIENTO COMERCIAL DEL SUICIDIO EN LA REPÚBLICA FEDERAL DE ALEMANIA. 1.1. Breve referencia a la regula-}

ción penal alemana en relación con la eutanasia y el suicidio asistido. 1.2. La controversia científica a propósito del $\S 217$ StGB. 2. EL DERECHO A UNA MUERTE AUTODETERMINADA EN LA REPÚBLICA FEDERAL DE ALEMANIA. 2.1. El ámbito de protección del derecho al libre desarrollo de la personalidad. 2.2. Los límites del derecho al libre desarrollo de la personalidad. 2.2.1. Los requisitos justificativos de la injerencia (I): su legítima finalidad, su adecuación y su necesidad. 2.2.2. Los requisitos justificativos de la injerencia (II): su adecuación o proporcionalidad en sentido estricto. 3. DOS COROLARIOS A MODO DE CONCLUSIÓN. 3.1 Corrección funcional y margen de discrecionalidad del legislador. 3.2. El Bundesverfassungsgericht y el derecho a la vida. 


\title{
SUICIDIO ASISTIDO Y LIBRE DESARROLLO DE LA PERSONALIDAD EN LA REPÚBLICA FEDERAL DE ALEMANIA
}

\author{
PABLO RIQUELME VÁZQUEZ ${ }^{1}$ \\ Universidade de Vigo \\ priquelme@uvigo.es
}

Entre los muchos «casos difíciles» ${ }^{2}$ a los que un jurista se puede llegar a enfrentar, los relacionados con la eutanasia y/o el suicidio asistido destacan por su especial complejidad $^{3}$. La solicitud de ayuda por parte de una persona para poner fin a su propia vida plantea desafíos moral y jurídicamente controvertidos en la mayor parte de los países de nuestro entorno ${ }^{4}$. En los últimos años, la «estatura constitucional» ${ }^{5}$ de esta espinosa problemática se ha puesto reiteradamente de manifiesto en sucesivos pro-

1 Estrada do Colexio Universitario, s/n; Campus Lagoas-Marcosende da Universidade de Vigo; 36310 Vigo (Pontevedra); priquelme@uvigo.es. El autor desea hacer constar su agradecimiento a Inma Valeije Álvarez, Alfredo Narváez Medécigo, Ángel Aday Jiménez Alemán y Marta García Mosquera por sus valiosas sugerencias y comentarios durante la fase de elaboración de este trabajo. Los errores que el mismo pueda contener son responsabilidad exclusiva del autor.

2 DWORKIN, R. (2012). Los derechos en serio. $1^{a}$ reimpr. (1ª ed., 1984) Barcelona: Ariel, pp. 146 y ss.

Los cambios en las nociones de vida y de muerte que han transformado el marco de referencia de las regulaciones jurídicas en relación con una y otra han sido estudiados en España por CHUECA RODRÍGUEZ, R. «El marco constitucional del final de la propia vida». Revista Española de Derecho Constitucional, núm. 85 (enero-abril 2009), pp. 99-123.

4 Vid., por citar sólo algunos autores, REY MARTÍNEZ, F. (2008). Eutanasia y derechos fundamentales. Madrid: Centro de Estudios Políticos y Constitucionales, pp. 38-78; FUCHS, M. y HÖNINGS, L. (2014). Sterbehilfe und Selbstbestimmtes Sterben. Zur Diskussion in Mittel- und Westeuropa, den USA, Kanada und Australien. Berlin: Konrad-Adenauer-Stiftung e.V., Sankt Augustin, p. 32-11; SANTOS ARNAIZ, J. A. (2017). Eutanasia y suicidio asistido en el debate contemporáneo: selección y análisis. Anuario de Derecho Eclesiástico del Estado, vol. XXXIII, pp. 795-804, o los más específicos trabajos reunidos en FORNASARI, G., PICOTTI, L. y VINCIGUERRA, S. (eds.). (2019). Autodeterminazione e aiuto al suicidio. Padova: Padova University Press, entre otros.

5 REY MARTÍNEZ, F. Eutanasia y derechos fundamentales, op. cit., pp. 82.

(C) UNED. Revista de Derecho Político 
nunciamientos de las jurisdicciones constitucionales italiana ${ }^{6}$, colombiana ${ }^{7}$ y canadiense $^{8}$ o del Tribunal Europeo de Derechos Humanos (en lo que sigue, TEDH) ${ }^{9}$, entre otros. A esta serie de resoluciones ha venido a sumarse la Sentencia de la sala segunda del Tribunal Constitucional Federal alemán (en lo sucesivo, BVerfG), de 26 de febrero de 2020, en los asuntos acumulados 2 BvR 2347/15, 2 BvR 651/16, 2 BvR 1261/16, 2 BvR 1593/16, 2 BvR 2354/16 y 2 BvR 2527/16 (en lo que sigue, BVerfGE de 26 de febrero de 2020). En esta resolución se resolvieron conjuntamente los recursos de amparo interpuestos por diversas asociaciones y profesionales médicos, así como por algunos particulares, contra el § 217 del Código Penal alemán (Strafgesetzbuch; en lo que sigue, StGB) en la redacción que al mismo le había dado la Ley para la punibilidad del favorecimiento comercial ${ }^{10}$ del suicidio, de 3 de diciembre de

6 GENTILE, G. (2020). «Il suicidio medicalmente assistito nello spazio libero dal diritto penale». Diritto penale e proceso. Mensile di giurisprudenza, legislazione e dottrina, 3/2020, pp. 377-388.

7 TOMÁS-VALIENTE LANUZA, C. (2019). «La evolución del derecho al suicidio asistido y la eutanasia en la jurisprudencia constitucional colombiana: otra muestra de una discutible utilización de la dignidad». Revista Española de Derecho Constitucional, núm. 116, pp. 301-328. Disponible en: https:// doi.org/10.18042/cepc/redc.116.10.

${ }^{8}$ Vid., al respecto, GIMBEL GARCÍA, J. F. (2016). «Eutanasia y suicidio asistido en Canadá. Una panorámica de la sentencia Carter v. Canadá y del consiguiente Proyecto de Ley C-14 presentado por el Gobierno canadiense». Revista de Derecho UNED, núm. 19, pp. 351-377. Disponible en: https://doi. org/10.5944/rduned.19.2016.18491; CAÑNAMRES ARRIBAS, S. (2016). «La reciente jurisprudencia del Tribunal de Estrasburgo y del Tribunal Supremo en Canadá en relación con el derecho a la muerte digna». Revista Española de Derecho Constitucional, núm. 108, pp. 337-356. Disponible en: http://dx.doi. org/10.18042/cepc/redc.108.11; o MARCHI, I. (2019). «Aiuto al suicidio, autodeterminazione e diritti fondamentali: spunti di riflessione alla luce dell'esperienza canadese e inglese». En FORNASARI, G., PICOTTI, L. y VINCIGUERRA, S. (eds.). Autodeterminazione e aiuto al suicidio. Padova: Padova University Press, pp. 36-39.

9 Se trata de las conocidas sentencias en los asuntos, Pretty $v$, the United Kingdom, de 29 de abril de 2002; Haas v. Switzerland, de 20 de enero de 2011; Koch v. Germany, de 19 de julio de 2012; Gross v. Switzerland, de 30 de septiembre de 2014; y Lambert and Others $v$. France, de 5 de junio de 2015. Vid., por todos, KORFF, D. (2006). The right to life. A guide to the implementation of Article 2 of the European Convention on Human Rights. Estrasburgo: Consejo de Europa, pp. 15-22; REY MARTÍNEZ, F. (2014). «La protección jurídica de la vida: un derecho en transformación y expansión (Arts. 2 CEDH y Protocolos $6^{\circ}$ y $13^{\circ}$ )». En GARCÍA ROCA, J. y SANTOLALLA, P. (coords.). La Europa de los derechos. El Covenio Europeo de Derechos Humanos. Madrid. Centro de Estudios Políticos y Constitucionales, pp. 71 y ss.; CAÑAMARES ARRIBAS, S. «La reciente jurisprudencia del Tribunal de Estrasburgo...», op. cit., pp. 341-347; y ARRUEGO, G. (2019). «Los confines del derecho fundamental a la vida». Revista Española de Derecho Constitucional, núm. 115, pp. 125-133. Disponible en: https://doi.org/10.18042/cepc/redc.115.04. En relación con el TEDH cabe igualmente destacar las decisiones de inadmisibilidad en los asuntos Sanles Sanles v. Spain, de 26 de octubre de 2000; Ada Rossi and Others v. Italy, de 16 de diciembre de 2008; Nicklinson and Lamb v. the United Kingdom, de 23 de junio de 2015; Gard and Others v. the United Kingdom, de 27 de junio de 2017; y Afiri and Biddarri v. France, de 23 de enero de 2018. En el momento de escribir estas líneas está pendiente de resolución el asunto Mortier v. Belgium (no. 78017/17).

10 Salvo indicación en contrario, se deberá entender que todos los fragmentos de texto en alemán citados literalmente en este trabajo han sido traducidos por el autor del mismo. Conforme a la exposición de motivos de la proposición de ley (Impresos del Parlamento Alemán [Drucksachen des Deutschen Bundestages; en lo que sigue, BTDrucks] 18/5373, p. 17), bastaría para caracterizar como «comercial 
$2015^{11}$. En una sentencia inusualmente larga ${ }^{12}$, el BVerfG otorgó el amparo a los recurrentes por la vulneración de una específica manifestación de su fundamental «derecho al libre desarrollo de la personalidad (allgemeine Persönlichkeitsrecht)» ${ }^{13}$ —concretamente, el «derecho a la muerte autodeterminada (Recht auf selbstbestimmtes Sterben)»-y declaró el $\S 217.1$ StGB nulo de pleno Derecho.

A continuación se exponen de forma necesariamente condensada los aspectos centrales de la controversia jurídica en relación con el favorecimiento comercial del suicidio en la República Federal de Alemania. La singularidad de la regulación impugnada y su reflejo sobre la argumentación del alto tribunal alemán no deben hacer perder de vista el trasfondo teórico de una decisión que ofrece una interesante respuesta sistemática ${ }^{14}$ a preguntas tan importantes para nuestro ordenamiento jurídico como: «¿Cuál es el sentido y alcance de la protección jurídica de la vida [...]?,

(geschäftsmäßig)» el favorecimiento llevado a cabo por una persona con la voluntad de hacer de la repetición de actos de igual naturaleza el objeto de su ocupación. Esto significa que la conducta no ha de perseguir necesariamente el enriquecimiento para ser punible: las actividades de voluntariado, por ejemplo, también serían subsumibles en el tipo [JARVERS, K. (2019). «La fattispecie tedesca di favoreggiamento del suicidio». En FORNASARI, G., PICOTTI, L. y VINCIGUERRA, S. (eds.). Autodeterminazione e aiuto al suicidio. Padova: Padova University Press, p. 54\}. Con la utilización de este concepto — geschäftsmäßigen un precepto penal se ha mostrado muy crítico ROXIN, C. (2016). «Die geschäftsmäßige Förderung einer Selbsttötung als Straftatbestand und der Vorschlag einer Alternative». Neue Zeitschrift für Strafrecht (NStZ), núm. 4, p. 189, entre otros. Para este autor, el término en cuestión no serviría para captar la verdadera finalidad de la prohibición impuesta por el $\S 217$ StGB. Además, el de la «comercialidad (Geschäftsmäßigkeit)» sería un criterio impreciso que generaría numerosas dificultades probatorias. Vid. infra, pp. 303-308.

11 Gesetzes zur Strafbarkeit der geschäftsmäßigen Förderung der Selbsttötung (Bundesgesetzblatt I, p. 2.177).

12 Para motivar su fallo, el alto tribunal alemán empleó 343 párrafos distribuidos en 96 páginas (de acuerdo con la versión que se puede imprimir desde la página web del BVerfG: https://www. bundesverfassungsgericht.de/SharedDocs/Entscheidungen/DE/2020/02/rs20200226_2bvr234715.html [fecha de la última consulta: 1 de marzo de 2020]). La inusual extensión de la sentencia lo llevó a acompañarla de una prolija tabla de contenidos. Esta minuciosidad puede ser interpretada como una manifestación de la cultura de la justificación auspiciada por el BVerfG y en la que tanto han insistido autores como FORST, R. (2007). Das Recht auf Rechtfertigung. Elemente einer konstruktivistischen Theorie der Gerechtigkeit. Frankfurt am Main: Suhrkamp, pp. 100-126 y 291-327, o KUMM, M. (2010). «The Idea of Socratic Contestation and the Right to Justification: The Point of Rights-Based Proportionality Review». Law E Ethics of Human Rights, vol. 4, núm. 2, pp. 140-175. En este sentido, por ejemplo, el alto tribunal alemán permitió que numerosos grupos y actores de la sociedad civil expresasen su postura, con arreglo al $\S 27$ a Ley del Tribunal Constitucional Federal (Bundesverfassungsgerichtsgesetz; en lo que sigue, BVerfGG), en calidad de terceros peritos (sachkundigen Dritten) y que otros lo hiciesen por iniciativa propia (BVerfGE de 26 de febrero de 2020, nn. mm. 142-177).

13 Vid., en lo que concierne al multifacético derecho al libre desarrollo de la personalidad, PIEROTH, B. y SCHLINK, B. (2005). Grundrechte. Staatsrecht II. 21 a ed. Heidelberg: C. F. Müller Verlag, pp. 88 y ss.; o STARCK, C. (2010). «Artikel 2 Absatz 2». En MANGOLDT, H. von, KLEIN, F. y STARCK, C. (eds.). Kommentar zum Grundgesetz: GG. Band 1: Präambel, Art. 1-19. 6a ed. München: Verlag Franz Vahlen, pp. 178-252, entre muchos otros.

14 La BVerfGE de 26 de febrero de 2020 enfatiza la dimensión constitucional de argumentos que, desde una perspectiva estrictamente penal, ya habían defendido JAKOBS, G. (1999). Suicidio, eutanasia y Derecho penal. Valencia: Tirant lo Blanch, p. 41, entre otros.

(C) UNED. Revista de Derecho Politico

N. ${ }^{\circ} 109$, septiembre-diciembre 2020, págs. 295-325 
¿existe un derecho a disponer de la propia vida?, ¿hay un derecho fundamental al suicidio?[,] ¿por qué el Derecho penal [alemán] no castiga a quien proporciona a otro que no quiere vivir más un veneno y sí lo hace — como autor de un delito de homicidio a petición- si le pone la inyección directamente?» ${ }^{15}$. En ese sentido, este estudio debería contribuir a una mejor valoración de las ventajas, inconvenientes y riesgos a tener en cuenta a la hora de regular ciertas formas de eutanasia o suicidio asistido $^{16}$. Con independencia de si el singular enfoque del BVerfG puede ser directamente importado a España —y de que la despenalización de la eutanasia y del suicidio asistido se pueda llevar a cabo a partir de premisas o modelos diferentes ${ }^{17}$-, la experiencia alemana no debería ser ignorada en el debate nacional al respecto.

En las páginas que siguen se presenta, en primer lugar, el marco jurídico de las decisiones sobre el final de la propia vida en Alemania y se expone críticamente la controvertida normativa penal en relación con la interdicción del favorecimiento comercial del suicidio. En segundo lugar, se analiza la fundamentación de la reciente sentencia del Tribunal Constitucional Federal alemán que declara inconstitucional la prohibición referida. Concretamente, en este apartado se presta una especial atención a la construcción doctrinal del derecho a una muerte autodeterminada efectuada por el supremo intérprete de la Ley Fundamental. Al hilo de la exposición y comentario de los problemas planteados por la regulación del suicidio asistido comercial en la República Federal de Alemania se efectúa, en tercer y último lugar, una reflexión sobre sus principales implicaciones para los equilibrios de poder entre órganos constitucionales y para la dogmática de los derechos fundamentales.

\section{LA PROHIBICIÓN DEL FAVORECIMIENTO COMERCIAL DEL SUICIDIO EN LA REPÚBLICA FEDERAL DE ALEMANIA}

\subsection{Breve referencia a la regulación penal alemana en relación con la eutanasia y el suicidio asistido}

Cualquier explicación del marco legal en que se insertan las decisiones sobre el final de la vida debe partir de que los avances técnicos en el ámbito médico han plan-

15 REY MARTÍNEZ, F. Eutanasia y derechos fundamentales, op. cit., pp. 83 y 140.

16 En España, como es sabido, la Mesa del Congreso de los Diputados decidió admitir a trámite el 31 de enero de este mismo año la Proposición de Ley Orgánica de regulación de la eutanasia presentada por el Grupo Parlamentario Socialista (Boletín Oficial de las Cortes Generales, Serie B, 21 de mayo de 2018, $\mathrm{n}^{\circ}$ 270-1) para su discusión en sede parlamentaria.

17 Vid., al respecto, ARRUEGO, G. (2008). «La naturaleza constitucional de la asistencia sanitaria no consentida y los denominados supuestos de «urgencia vital»». Revista Española de Derecho Constitucional, núm. 82, pp. 73-80; REY MARTÍNEZ, F. Eutanasia y derechos fundamentales, op. cit., pp. 83-88; TOMÁSVALIENTE LANUZA, C. (2016). «La eutanasia: marco legal en España y encaje del posible derecho a disponer de la propia vida». En AA. VV. Eutanasia y suicidio asistido. Cuadernos de la Fundació Víctor Grífols i Lucas, núm. 41, pp. 68 y ss. 
teado los más intrincados problemas en relación con los límites de la responsabilidad criminal ${ }^{18}$. Alemania representa una suerte de excepción a la tendencia, algo generalizada en el centro de la Europa occidental, a la despenalización de la eutanasia ${ }^{19}$. Como han explicado con claridad Montalvo y Sánchez ${ }^{20}$, la regulación relevante a este respecto se encontraba, antes de la reintroducción del $§ 217$ StGB, dispersa en el $\S$

18 LINDEMANN, M. y MEVIS, P. (2016). «Recent developments in the legislation and case-law on euthanasia and assisted suicide. A comparative analysis of the situation in Germany and the Netherlands». En HRUSCHKA, J., y JOERDEN, J. C. (eds.). Jabrbuch für Recht und Ethik - Annual Review of Law and Ethics. Berlin: Duncker \& Humblot, Editors, pp. 357-387. Con razón se ha dicho que la «discusión en torno a la muerte asistida es históricamente reciente y se ha hecho más presente en las sociedades ricas y avanzadas, donde morir es un proceso medicalizado que además se torna estatal allí donde existen sistemas públicos de salud» (ARRUEGO, G. «Los confines del derecho fundamental a la vida», op. cit., p. 116).

19 Vid. NOSEDA, J. (2019). «La legislazione svizzera sull'assistenza al suicidio». En FORNASARI, G., PICOTTI, L. y VINCIGUERRA, S. (eds.). Autodeterminazione e aiuto al suicidio. Padova: Padova University Press, pp. 71-76; BONIFACIO, G. (2019). «L'eutanasia nei Paesi Bassi». En FORNASARI, G., PICOTTI, L. y VINCIGUERRA, S. (eds.). Autodeterminazione e aiuto al suicidio. Padova: Padova University Press, pp. 77-84; LINDEMANN, M. y MEVIS, P. «Recent developments in the legislation...», op. cit., pp. 357-387; FUCHS, M. y HÖNINGS, L. Sterbebilfe und Selbstbestimmtes Sterben..., op. cit., pp. 46-73; RUIZ MIGUEL, A. (2010). «Autonomía individual y derecho a la propia muerte». Revista Española de Derecho Constitucional, núm. 89, pp. 15 y ss., o REY MARTÍNEZ, F. Eutanasia y derechos fundamentales, op. cit., pp. 46-61, entre otros. La regulación penal se endurece nuevamente a medida que nos desplazamos hacia el sur — tal y como explican HELFER, M. (2019). «Aiuto al suicidio. Autodeterminazione e diritti fondamentali in Austria». En FORNASARI, G., PICOTTI, L. y VINCIGUERRA, S. (eds.). Autodeterminazione e aiuto al suicidio. Padova: Padova University Press, pp. 13-32; PARIZOT, R. (2019). «Aiuto al suicidio: quale approccio in Francia?». En FORNASARI, G., PICOTTI, L. y VINCIGUERRA, S. (eds.). Autodeterminazione e aiuto al suicidio. Padova: Padova University Press, pp. 43-52; QUINTERO OLIVARES, G. (2019). «Auxilio al suicidio y eutanasia en España». En FORNASARI, G., PICOTTI, L. y VINCIGUERRA, S. (eds.). Autodeterminazione e aiuto al suicidio. Padova: Padova University Press, pp. 63-70; o VINCIGUERRA, S. (2019). «L'aiuto al suicidio in Italia (art. 580 c.p.). Alcune osservazioni fra storia e attualità». En FORNASARI, G., PICOTTI, L. y VINCIGUERRA, S. (eds.). Autodeterminazione e aiuto al suicidio. Padova: Padova University Press, pp. 85-94- o cruzamos el Canal de la Mancha. La sección 2.1 de la Suicide Act británica de 1961 (Chapter 60, Regnal. 9 y 10, Eliz 2), por ejemplo, prohíbe expresamente el suicidio asistido. La eutanasia voluntaria (voluntary eutanasia) también está castigada por el derecho británico que, sólo en ciertos casos, la considera un homicidio involuntario (manslaughter). Vid., al respecto, McCALL SMITH, A. (1996). «Euthanasia: the law in the United Kingdom». British Medical Bulletin, vol 52, núm. 2, pp. 334-340. Disponible en: https://doi.org/10.1093/oxfordjournals.bmb. a011548. Autores como PICOTTI, L. (2019). «Aiuto al suicidio, autodeterminazione, diritti fondamentali: uno sforzo di sintesi». En FORNASARI, G., PICOTTI, L. y VINCIGUERRA, S. (eds.). Autodeterminazione e aiuto al suicidio. Padova: Padova University Press, pp. 171-175, han reconocido, desde el punto de vista del Derecho comparado, «cuatro modelos de reglamentación de la materia»: el tradicional (de Austria, España o Italia), el intermedio (de Alemania o Francia), el anglosajón (de Canadá o Reino Unido) y el liberalizado (de Suiza o Países Bajos).

20 MONTALVO JÄÄSKELÄINEN, F. y SÁNCHEZ BARROSO, B. (2019). «La regulación de la eutanasia y el suicidio asistido en Alemania: ¿una excepcionalidad o un modelo europeo basado en la dignidad humana?». En MARCOS DEL CANO, A. M. (ed. lit.) y TORRE DÍAZ, F. J. de la (ed. lit.). $Y$ de nuevo la eutanasia: Una mirada nacional e internacional. Madrid: Dykinson, pp. 183-189.

(C) UNED. Revista de Derecho Político

N. ${ }^{\circ} 109$, septiembre-diciembre 2020, págs. 295-325 
216 StGB, el § 1901 a del Código civil alemán (Bürgerliches Gesetzbuch, más conocido como BGB $)^{21}$ y el $\S 5.1 .6$ de la Ley de estupefacientes ${ }^{22}$.

No es posible (y seguramente carece de sentido) desarrollar aquí todos y cada uno de los detalles de esta regulación ${ }^{23}$. A los efectos que ahora interesan basta con señalar que, en el momento de la entrada en vigor del $\S 217$ StGB, el Derecho penal vigente en Alemania no castigaba ni el suicidio ni, en principio, la participación en el mis$\mathrm{mo}^{24}$. En concreto gozaba de impunidad la participación en el suicidio (inducido o no) de un tercero, siempre y cuando esta participación no implicase un «dominio del hecho (Tatherrschaft)» ${ }^{25}$. De esta «ayuda o auxilio al suicidio (Suizidhilfe)» hay que distinguir la «ayuda a morir (Sterbehilfe)» (o eutanasia lato sensu) ${ }^{26}$. Esta última engloba una multiplicidad de conductas en las que, a diferencia de lo que ocurre en el suicidio asistido, es una actuación dominada por un tercero la que conduce causalmente a un acortamiento de la vida o lo favorece de otras formas. En estos casos, el desvalor social y jurídico sólo recae hoy en día sobre la eutanasia activa directa ${ }^{27}$, la cual —en tanto

21 En la redacción fijada por la Tercera Ley para la modificación del Derecho asistencial, de 29 de julio del año 2009 (Dritte Gesetz zur Änderung des Betreuungsrechts, BGBl I, p. 2.286).

22 Gesetz über den Verkehr mit Betäubungsmitteln (más conodica como Betäubungsmittelgesetz o BtMG) en la versión vigente desde el 1 de marzo de 1994 (BGBl. I, p. 358) y modificada por última vez el 2 de julio de 2018 (BGB1. I, p. 1.078).

${ }_{23}$ Vid., sobre el particular, LINDEMANN, M. y MEVIS, P. «Recent developments in the legislation...», op. cit., o FUCHS, M. y HÖNINGS, L. Sterbebilfe und Selbstbestimmtes Sterben..., op. cit., pp. 32-45. Una exposición más amplia de la protección penal de la vida en Alemania puede consultarse en ESER, A. y STERNBERG-LIEBEN, D. (2019). «16. Abschnitt. Straftaten gegen das Leben $(\S \S$ 211-222)». En SCHÖNKE, A. et al. Strafgesetzbuch Kommentar. München: C. H. Beck, pp. 2.055-2.225.

24 Una cuestión tradicionalmente controvertida en el Derecho penal alemán es la que atañe a la punibilidad de la persona que, ocupando una posición de garante sobre la víctima, la deja morir o suicidarse. En principio, la ayuda al suicidio no es punible, pero la doctrina científica alemana ha denunciado (y criticado) cierta tendencia jurisprudencial a servirse de la figura de la comisión por omisión para imponer (ex $\S 216$ StGB) a la persona que presencia un suicidio la obligación de salvar a la o el suicida tan pronto como esta o este entra en estado de inconsciencia (FUCHS, M. y HÖNINGS, L. Sterbehilfe und Selbstbestimmtes Sterben..., op. cit., 33 y s.).

25 ESER, A. (1985). «Sterbewille und ärztliche Verantwortung. Zugleich Stellungnahme zum Urteil des BGH im Fall Dr. Wittig». Medizinrecht, vol. 3, núm. 1, p. 8.

26 Vid., en relación con las causas de la elusión de la palabra «Euthanasie» en el debate público alemán, MONTALVO JÄÄSKELÄINEN, F. y SÁNCHEZ BARROSO, B. «La regulación de la eutanasia y el suicidio asistido...», op. cit., p. 178.

27 A la luz de la jurisprudencia de los tribunales ordinarios alemanes cabe distinguir dos supuestos de impunidad de la ayuda a morir: la «ayuda indirecta a morir (indirekte Sterbehilfe)» (o eutanasia activa indirecta) y la «interrupción del tratamiento (Behandlungsabbruch)» (o eutanasia pasiva). Naturalmente, ambas modalidades presuponen en la afectada o afectado una voluntad expresa o presunta de acabar con su propia vida. Vid., en relación con el problema de los testamentos vitales y la determinación de la voluntad del paciente, la Sentencia del Bundesgerichtshof de 17 de septiembre de 2014, en el asunto ZB 202/13, nn. mm. 35-38. La eutanasia pasiva no es punible, conforme a la jurisprudencia reiterada de la máxima instancia judicial alemana, cuando consista en una interrupción del tratamiento médico (o las correspondientes medidas de conservación de la vida) prescrito(s) para alargar o mantener de forma artificial la vida del paciente. En tales casos, además, las acciones u omisiones solo se considerarán penalmente irrelevantes cuando la enfermedad del paciente implique irreversiblemente su muerte 
que «homicidio consensuado (einverständliche Fremdtötung)» u «homicidio a petición (Tötung auf Verlangen)»— se castiga en el $§ 216$ StGB para «garantizar que la voluntad del que no quiere vivir más sólo se realice cuando sea subjetivamente madura, es decir, que se fundamente completamente en que sea el que no quiere vivir más el que determine el fin, sin necesidad de que sea revisado por otro ${ }^{28}$. Esta regulación fue tempranamente caracterizada por Eser como un «término medio» entre la prohibición de matar a otro y la libertad de suicidarse en el contexto de peticiones de ayuda para poner fin a la propia vida ${ }^{29}$.

El 10 de diciembre de 2015 entraba en vigor la Ley para la punibilidad del favorecimiento comercial del suicidio, la cual introducía en el ordenamiento vigente el nuevo $§ 217 \mathrm{StGB}^{30}$ :

Favorecimiento comercial del suicidio

(1) Quien, con la finalidad de favorecer el suicidio de otro, le confiera, proporcione o facilite comercialmente la ocasión para ello, será castigado con pena de prisión de hasta tres años o multa.

(2) No será castigado el partícipe ${ }^{31}$ que no actúe comercialmente y sea pariente del otro mencionado en el primer párrafo o esté íntimamente vinculado a él.

Esta redacción, que fue adoptada por el Bundestag después de un intenso debate ${ }^{32}$, era la inicialmente prevista en la proposición de ley para la punibilidad del favoreci-

(Sentencia del Bundesgerichtshof de 25 de junio de 2010, en el asunto 2 StR 454/09, nn. mm. 31 y ss.). En la Sentencia del Bundesgerichtshof de 15 de noviembre de 1996, por su parte, se despenaliza la eutanasia activa indirecta porque: «posibilitar la muerte en dignidad y sin dolor de acuerdo con la voluntad expresa o tácita del paciente es un bien jurídico de mayor rango que la perspectiva de tener que vivir un poco más de tiempo bajo graves [...] dolores destructivos» (Sentencia del Bundesgerichtshof de 15 de noviembre de 1996, en el asunto 3 StR 79/96, n. m. 25).

28 JAKOBS, G. Suicidio, eutanasia y Derecho penal, op. cit., p. 53. Vid., en relación con el fundamento de esta distinción, infra, pp. 320-323. Cabe señalar que ROXIN, C. (2001). «Tratamiento jurídico-penal de la eutanasia». En VV. AA. Eutanasia y suicidio. Cuestiones dogmáticas y de política criminal. Granada: Comares, p. 35, ha sugerido de lege ferenda que se excluya la responsabilidad del auxiliar que ejecuta la muerte deseada por el que padece «una grave situación de sufrimiento insoportable [...] que no pueda ser evitada o mitigada por ninguna otra medida».

29 ESER, A. «Sterbewille und ärztliche Verantwortung...», op. cit., p. 7.

30 «Geschäftsmäßige Förderung der Selbsttötung

(1) Wer in der Absicht, die Selbsttötung eines anderen zu fördern, diesem bierzu geschäftsmäßig die Gelegenheit gewährt, verschafft oder vermittelt, wird mit Freiheitsstrafe bis zu drei Jahren oder mit Geldstrafe bestraft.

(2) Als Teilnehmer bleibt straffrei, wer selbst nicht geschäftsmäßig handelt und entweder Angehöriger des in Absatz 1 genannten anderen ist oder diesem nahesteht».

31 Conforme al $\$ 28$ StGB, son partícipes del delito el «inductor (Anstifter)» (§ $26 \mathrm{StGB}$ ) y el «cómplice (Gehilfe)» (§ 27 StGB).

32 Tal y como explica ROXIN, C. «Die geschäftsmäßige Förderung...», op. cit., pp. 185 y ss., la proposición de ley ocasionó un importante debate en el que no sólo participaron políticos y los especialistas académicos en la materia, sino también multitud de asociaciones y otros representantes de la sociedad civil. Vid., en el mismo sentido, JARVERS, K. «La fattispecie tedesca...», op. cit., p. 58.

(C) UNED. Revista de Derecho Político

303

N. ${ }^{\circ} 109$, septiembre-diciembre 2020, págs. 295-325 
miento comercial del suicidio ${ }^{33}$. En principio, el $\S 217$ StGB no había tenido la finalidad de poner en entredicho la impunidad del suicidio y de la participación en el mismo. La nueva norma únicamente perseguía intervenir coercitivamente donde «ofertas comerciales» de ayuda a suicidarse amenazaban la autodeterminación y la $v_{\text {vida }}{ }^{34}$. La regulación precedente había permitido la proliferación de ofertas de auxilio al suicidio procedentes de organizaciones e incluso particulares, generando con ello un serio peligro para la autonomía decisoria de miembros vulnerables de la sociedad. El legislador alemán temía particularmente una normalización ${ }^{35}$ del suicidio como forma de terminación de la vida entre personas gravemente enfermas o ancianas que, en su opinión, nunca tomarían una decisión semejante en ausencia de tales ofertas ${ }^{36}$. El objetivo de la norma era, así, el de contrarrestar esta tendencia, evitando con ello una proliferación indeseada del suicidio asistido.

Con la regulación se penalizaba, por su condición de «actuación abstractamente amenazante de la vida», el otorgamiento, puesta a disposición o facilitación comerciales de una ocasión para suicidarse ${ }^{37}$, sin que fuesen necesarias para realizar el tipo penal la materialización efectiva o la tentativa del suicidio. El supuesto de hecho se entendía realizado con tal de que las actuaciones llevadas a cabo resultasen objetivamente idóneas para favorecer el suicidio, quedando correlativamente excluidas aquellas insuficientes a tal fin, como los simples intercambios de información ${ }^{38}$. Bajo el tipo sólo cabía subsumir actividades comerciales lato sensu, es decir, actividades recurrentes o permanentes protagonizadas por el sujeto activo, al margen de si las mismas constituían su actividad profesional o se realizaban con ánimo de lucro ${ }^{39}$. Ello

33 Entwurf eines Gesetzes zur Strafbarkeit der geschäftsmäßigen Förderung der Selbsttötung (BTDrucks 18/5373).

34 BTDrucks, 18/5373, pp. 11 y s., y 17.

35 Concretamente, en la proposición de ley se aludía al riesgo de «normalización social (gesellschaftliche Normalisierung)»y al «(efecto de) acostumbramiento o habituación (Gewöhnungseffekt)» (BTDrucks, 18/5373, pp. 2 y s.) concomitante con tales ofertas. Al peso en la conciencia alemana del conocido argumento de la «pendiente resbaladiza» se han referido MONTALVO JÄÄSKELÄINEN, F. y SÁNCHEZ BARROSO, B. «La regulación de la eutanasia y el suicidio asistido...», op. cit., p. 181. En España también se ha empleado la fórmula «rotura de diques» (REY MARTÍNEZ, F. Eutanasia y derechos fundamentales, op. cit., pp. 192) para referirse a esta amenaza. RUIZ MIGUEL, A. "Autonomía individual y derecho a la propia muerte», op. cit., p. 35, o TOMÁS-VALIENTE LANUZA, C. «La eutanasia: marco legal en España...», op. cit., p. 87, se han mostrado muy críticos con este tipo de razonamientos. En opinión de la segunda, por ejemplo, con esta fórmula se «pretende justificar la prohibición de algo no intrínsecamente malo por el uso que se podría hacer de ello. Quienes utilizan este argumento pronostican, en caso de la despenalización de la eutanasia, un auténtico holocausto a expensas de las personas más vulnerables». La actuación del legislador alemán en el caso aquí analizado fue calificada por ROXIN, C. «Die geschäftsmäßige Förderung...», op. cit., p. 188, como «una forma de paternalismo suave».

36 ROXIN, C. «Die geschäftsmäßige Förderung...», op. cit., p. 187.

37 WEIGEND, T. y HOVEN, E. (2016). «§ 217 StGB - Bemerkungen zur Auslegung eines zweifelhaften Tatbestandes». Zeitschrift für Internationale Strafrechtsdogmatik (ZIS), 10/2016, 11. Jahrgang, pp. 684 y ss.

38 JARVERS, K. «La fattispecie tedesca...», op. cit., p. 56.

39 BTDrucks 17/11126, pp. 9 y s. 
suponía que el favorecimiento del suicidio no se debía castigar cuando, además respetar una decisión autónomamente adoptada por la persona resuelta a morir, se realizaba de manera puntual ${ }^{40}$.

Desde un punto de vista hermenéutico, el precepto complicaba un tanto las cosas al regular, en su segundo apartado, las causas de exclusión de la responsabilidad penal de los partícipes. Al contrario que los autores del tipo, el inductor o el cómplice (p. ej., la persona que, con pleno conocimiento de las consecuencias de su acción, transportase a otra resuelta a quitarse la vida a la sede de una organización que se ha comprometido a ayudar a la última a suicidarse) sólo podían eludir el castigo en caso de no actuar comercialmente y ser, además, allegados o parientes ( $\$ 11$ StGB) de la persona resuelta a morir. Así, mientras que la autora o autor de la conducta descrita en el párrafo primero sólo podía ser castigado al obrar comercialmente, la o el partícipe, aún actuando de manera «puntual», sólo eludía el castigo en caso de ser familiar o allegado. Los médicos y el restante personal sanitario no se encontraban, desde luego, en el círculo de sujetos mencionados en el párrafo segundo ${ }^{41}$.

\subsection{La controversia científica a propósito del $\$ 217$ StGB}

A pesar de su loable propósito, el tenor literal del § 217 StGB enseguida suscitó las críticas y reparos de numerosos penalistas alemanes, los cuales, en el mejor de los casos, le achacaron el defecto de conducir a una «situación absurda» ${ }^{42}$. El examen de sus planteamientos dogmáticos reviste interés en la medida en que puede arrojar luz sobre los argumentos empleados por el BVerfG en su sentencia de 26 de febrero de 2020, que se analizará posteriormente. El perfil marcadamente constitucional de muchos de los razonamientos presentes en la literatura científica alemana en relación con el $§ 217$ StGB permite concebirlos como algo más que meros tecnicismos o simples consideraciones de política criminal; no en vano, por ejemplo, los recursos de amparo que dieron lugar a la sentencia aludida se hicieron eco de una parte importante de tales razonamientos. Indudablemente, las pretensiones de las y los recurrentes ante el alto tribunal alemán se articularon en torno a un elemento ausente de o secun-

40 ROXIN, C. «Die geschäftsmäßige Förderung...», op. cit., p. 189.

41 KUHLI, M. (2017). «Absehbare Anwendungsprobleme des § 217 StGB?». Zeitschrift für die gesamte Strafrechtswissenschaft (ZStW), vol. 129, núm. 3, p. 713. Disponible en: https://doi.org/10.1515/ zstw-2017-0035. Los facultativos alemanes no sólo no están obligados a ayudar a una persona a suicidarse —puesto que la «participación del médico en el suicidio no es una tarea médica» [HOPPE, J.-D. (2011). «Grundsätze der Bundesärztekammer zur ärztlichen Sterbebegleitung». Deutsches Ärzteblatt, Jahrgang. 108, Heft 7, p. 346; ROXIN, C. «Tratamiento jurídico-penal de la eutanasia», op. cit., p. 33]—, sino que el $\$ 16$ del «Reglamento profesional (modelo) [(Muster-)Berufsordnung]» (DOI: 10.3238/ arztebl.2019.mbo_daet2018b) elaborado en sucesivos congresos médicos alemanes prohíbe taxativamente que los facultativos presten cualquier tipo de ayuda al suicidio de un paciente. Según JARVERS, K. «La fattispecie tedesca...», op. cit., p. 54, la opinión de los médicos se encuentra dividida al respecto.

42 JARVERS, K. «La fattispecie tedesca...», op. cit., p. 58.

(C) UNED. Revista de Derecho Politico

N. ${ }^{\circ} 109$, septiembre-diciembre 2020, págs. 295-325 
dario en los trabajos de los penalistas, a saber, la vulneración bien del derecho al libre desarrollo de la personalidad enunciado en el art. 2.1 GG GG $^{43}$, bien de algunas de las manifestaciones de dicho derecho en conexión con el art. 1.1 GG —en particular, el derecho de autodeterminación (Selbstbestimmungsrecht) ${ }^{44}$ o un «derecho a morir (Recht auf Sterben)» que no sólo facultaría a su titular para disponer fácticamente de su propia vida, sino para recurrir con tal propósito a la ayuda de terceros ${ }^{45}$ —; sin embargo, la conveniencia ${ }^{46}$ de examinar con el máximo rigor las decisiones legislativas en una materia tan controvertida como esta no puede ignorar (especialmente en lo tocante a la proporcionalidad de la medida) algunos de los defectos y patologías ${ }^{47}$ denunciados en sede científica. En pocas palabras, la discusión doctrinal puede ayudar a valorar adecuadamente la medida en que el «Derecho penal [...] tiene competencia en los casos de auxilio a un suicidio responsable» ${ }^{48}$.

De acuerdo con un esquema tripartito inspirado en la versión más difundida del principio de proporcionalidad ${ }^{49}$, se puede decir que los especialistas alemanes en la materia formularon reparos en relación con la idoneidad del $\S 217$ StGB para alcanzar el fin perseguido por el legislador, su necesidad (o condición de medio más benigno con los bienes o derechos colateralmente afectados) y/o su adecuación (o proporcionalidad en sentido estricto $)^{50}$.

En primer lugar, diversos autores señalaron que la finalidad perseguida por el legislador — a saber, proteger a las personas resueltas a suicidarse de actuaciones precipitadas o de la influencia de terceros — sólo podía lograrse de una forma efectiva a través de garantías que no se dan en supuestos de suicidio asistido no comercial; los ayudantes legos, «confrontados inesperadamente en el caso de conflicto con la situación, no suelen disponer de la competencia necesaria para contrarrestar manipulaciones e influencias de la responsabilidad libre o simplemente para mostrarle al que desea

43 BVerfGE de 26 de febrero de 2020, nn. mm. 69 y s., y 86.

44 BVerfGE de 26 de febrero de 2020, nn. mm. 35 y ss. Otros recurrentes optaron por expresiones análogas como «derecho de autodeterminación sobre la propia muerte (Selbstbestimmungsrecht über den eigenen Tod)» (BVerfGE de 26 de febrero de 2020, nn. mm. 87 y ss.) o «decisión autodeterminada sobre la propia muerte (selbstbestimmte Entscheidung über das eigene Sterben)» (BVerfGE de 26 de febrero de 2020, nn. mm. 54 y ss.).

45 BVerfGE de 26 de febrero de 2020, n. m. 87.

46 Vid., en relación con los motivos que pueden justificar una más intensa supervisión de la obra del legislador en casos como el aquí discutido, infra, pp. 312 y ss.

47 KUMM, M. «The Idea of Socratic Contestation...», op. cit., pp. 157-164.

48 ROXIN, C. «Die geschäftsmäßige Förderung...», op. cit., p. 192.

49 Vid., por todos, ALEXY, R. (2007). Teoría de los derechos fundamentales. $2^{\mathrm{a}}$ ed. (1 $\left.{ }^{\mathrm{a}} \mathrm{ed} ., 2001\right)$. Madrid: Centro de Estudios Políticos y Constitucionales, pp. 523-546; o BERNAL PULIDO, C. (2007). El principio de proporcionalidad y los derechos fundamentales. El principio de proporcionalidad como criterio para determinar el contenido de los derechos fundamentales vinculante para el legislador. $3^{\mathrm{a}}$ ed. Madrid: Centro de Estudios Políticos y Constitucionales.

50 Por proporcionalidad en sentido estricto se entiende aquí, siguiendo a BERNAL PULIDO, C. El principio de proporcionalidad..., op. cit., pp. 765-785, la «determinación de la importancia de la intervención en el derecho fundamental» cuya vulneración se alega. 
morir opciones alternativas vitalistas $»^{51}$. Irónicamente, la criminalización del favorecimiento comercial del suicidio podía terminar forzando a la persona resuelta a morir a escoger otras formas de suicidio no sólo no deseadas por ella, sino eventualmente más inseguras ${ }^{52}$ o que requiriesen un desplazamiento a otro país ${ }^{53}$. Estas razones ponían seriamente en entredicho la idoneidad de la reforma legislativa para alcanzar el objetivo perseguido.

En segundo lugar, la naturaleza fragmentaria y de ultima ratio del Derecho penal hacía la medida innecesaria, ya que la finalidad perseguida podía ser alcanzada a través de una adecuada regulación administrativa ${ }^{54}$. El legislador no había podido valorar adecuadamente la presunta peligrosidad del favorecimiento comercial del suicidio y, a falta de la adecuada base empírica, habría sido conveniente una mayor «circunspección en la criminalización y [...] una búsqueda de posibilidades de intervención menos intensas» ${ }^{55}$.

En tercer lugar, la adecuación o proporcionalidad en sentido estricto de la medida también había sido puesta en entredicho desde diferentes ángulos. Desde una perspectiva constitucional —es decir, una que tomase en consideración que la GG no ofrece una garantía absoluta de la vida, sino que el derecho fundamental a la misma ha de ser cohonestado con el respeto del libre desarrollo de la personalidad y de la dignidad humana ${ }^{56}$ - el $\S 217$ StGB comportaba una penalización desproporcionada por desconocer a todos los efectos el valor constitucional de la autodeterminación individual ${ }^{57}$. Adicionalmente, el precepto cuestionado se reputaba contrario al principio de igualdad. ¿Qué razones había para castigar el favorecimiento comercial de un suicidio como delito de peligro abstracto, dejando, al mismo tiempo, impune la participación en

51 DUTTGE, G. (2016). «Strafrechtlich reguliertes Sterben. Der neue Straftatbestand einer geschäftsmäßigen Förderung der Selbsttötung». Neue Juristische Wochenschrift (NJW), vol. 69, núm. 3, pp. 122 y s. Vid., en el mismo sentido, ROXIN, C. «Die geschäftsmäßige Förderung...», op. cit., p. 188, así como la BVerfGE de 26 de febrero de 2020, nn. mm. 44, 51 y 60.

52 WEIGEND, T. y HOVEN, E. «§ 217 StGB - Bemerkungen...», op. cit., p. 683.

53 La proximidad geográfica entre Alemania y Suiza provoca que los ciudadanos del primer país recurran, en ciertos casos, a la ayuda al suicidio ofrecida en el segundo. Esta situación se puso de manifiesto, por ejemplo, con motivo de la STEDH, de 19 de julio de 2012, en el caso Koch v. Germany.

54 BVerfGE de 26 de febrero de 2020, nn. mm. 51 y 79.

55 ROXIN, C. «Die geschäftsmäßige Förderung...», op. cit., p. 188.

56 Según ARRUEGO, G. «Los confines del derecho fundamental a la vida», op. cit., p. 129, este enfoque informa la jurisprudencia más reciente del TEDH. Para este autor, la modulación del «alcance atribuido al deber de protección de la vida (art. $2 \mathrm{CEDH}$ ), a través de la progresiva inserción del principio de autonomía individual y del encaje de las decisiones sobre el final de la vida propia en el art. $8 \mathrm{CEDH}$ » impediría seguir oponiendo el art. $2 \mathrm{CEDH}$ a «la decisión libre y responsable de quien resuelve terminar con su existencia». Todo ello no sería sino parte de la «transformación desde una cultura dominada por la primacía del valor de la vida que otorga un papel predominante y paterna lista a la sociedad, y dentro de ella al personal sanitario, a una cultura en la que la autonomía del propio individuo interesado comienza a tener una relevancia hasta muy recientemente apenas reconocida pero que debe ser bienvenida» (RUIZ MIGUEL, A. «Autonomía individual y derecho a la propia muerte», op. cit., p. 12).

57 JARVERS, K. «La fattispecie tedesca...», op. cit., p. 59. Vid. BVerfGE de 26 de febrero de 2020, nn. mm. 37 y s, 40,53 y s., y 87.

(C) UNED. Revista de Derecho Politico

307

N. ${ }^{\circ} 109$, septiembre-diciembre 2020, págs. 295-325 
dicho favorecimiento de parientes o allegados? Complementariamente se señaló que, desde un punto de vista penal, un acto lícito no puede devenir punible sólo porque exista la intención de repetirlo, especialmente cuando con el mismo no se dañe o amenace un bien jurídico protegido ${ }^{58}$, y este reproche se combinó, a su vez, con aquel otro según el cual el criterio de la comercialidad no permitía determinar unívocamente si y en qué condiciones los médicos que prestaban asistencia para el suicidio en el ámbito de su actividad profesional debían ser castigados ${ }^{59}$. Según el tenor literal de la norma, cabía en principio considerar como autores a los facultativos, "puesto que un médico que hace de la repetición de actos de igual naturaleza el objeto de su actividad, practica el favorecimiento comercial del suicidio» ${ }^{60}$. Desde esta perspectiva no debe extrañar que algunos recurrentes considerasen que también se había vulnerado su derecho a escoger libremente una profesión reconocido en el art. $12.1 \mathrm{GG}^{61}$.

Todos estos argumentos, no obstante, solo cobran pleno sentido sobre el trasfondo de un razonamiento construido en torno a uno o varios derechos fundamentales. En otras palabras, las consideraciones expuestas necesitan, para desarrollar todo su potencial jurídico, de una «teoría sustantiva» de los derechos fundamentales ${ }^{62}$ sin la cual resulta imposible determinar el «espacio de valoración cambiante que sólo encontrará en la Constitución los perfiles contramayoritarios, tan necesarios, en materia de derechos fundamentales» ${ }^{63}$. Precisamente esto es lo que hace apenas unos meses demostró la sentencia del Tribunal Constitucional Federal alemán que declaró inconstitucional la prohibición de favorecimiento comercial del suicidio.

58 ROXIN, C. «Die geschäftsmäßige Förderung...», op. cit., p. 188. Vid. BVerfGE de 26 de febrero de 2020 , nn. mm. 69 y 87.

59 ROXIN, C. «Die geschäftsmäßige Förderung...», op. cit., p. 190. Vid. BVerfGE de 26 de febrero de 2020, n. m. 74 .

60 WEIGEND, T. y HOVEN, E. «\$217 StGB — Bemerkungen...», op. cit., p. 689.

61 Además de los derechos al libre desarrollo de la personalidad y a escoger libremente una profesión, los recurrentes consideraron vulnerados sus derechos a la vida (art. 2.2 GG) (BVerfGE de 26 de febrero de 2020, n. m. 87), a no ser castigados por una norma penal retroactiva (art. 103.2 GG) (BVerfGE de 26 de febrero de 2020, nn. mm. 69 y 86) o a la propiedad privada (art. 14.1 GG) (BVerfGE de 26 de febrero de 2020, n. m. 69), y sus libertades de asociación (art. 9.1 GG) (BVerfGE de 26 de febrero de 2020, n. m. 47) y conciencia (BVerfGE de 26 de febrero de 2020, nn. mm. 70, 78 y 86). Estas últimas pretensiones, sin embargo, serían desestimadas por el BVerfG.

${ }^{62}$ FERRERES COMELLA, V. (2018). «Beyond the principle of proportionality». En JACOBSOHN, G. y SCHOR, M. (eds.). Comparative Constitutional Theory. Cheltenham/Northampton: Edward Elgar Publishing, p. 231. A mi entender, la necesidad de semejante teoría también se colige de la respuesta de Alexy a la crítica que Matthias Jestaedt y Alexander Somek han dirigido contra la teoría de la ponderación: «[La determinación del peso abstracto de los principios en conflicto] se puede llevar a cabo solamente mediante la argumentación. Por lo tanto, la fórmula del peso resulta ser un argumento perteneciente al discurso jurídico racional. Como tal, ella se hace imprescindible para poder introducir «orden al pensamiento jurídico». Esto pone en claro qué puntos son los decisivos y cómo dichos puntos se relacionan los unos con los otros» [ALEXY, R. (2011). «Los derechos fundamentales y el principio de proporcionalidad». Revista Española de Derecho Constitucional, núm. 91, p. 28 (énfasis añadido)].

63 CHUECA RODRÍGUEZ, R. «El marco constitucional...», op. cit., p. 105. 


\section{EL DERECHO A UNA MUERTE AUTODETERMINADA EN LA REPÚBLICA FEDERAL DE ALEMANIA}

En su sentencia de 26 de febrero de 2020, el BVerfG focalizó su atención en las alegaciones de los recurrentes para los que la prohibición del favorecimiento comercial del suicidio impuesta por el $\S 217$ StGB vulneraba su derecho a una muerte autodeterminada ${ }^{64}$. Como se verá, el tribunal de Karlsruhe efectuó la valoración de tales pretensiones en tres etapas consecutivas: en primer lugar, analizó el «ámbito de protección (Schutzbereich)» abarcado por dicho derecho; en segundo lugar, constató la «injerencia» legislativa en el mismo; y, en tercer lugar, comprobó su «justificación constitucional».

\subsection{El ámbito de protección del derecho al libre desarrollo de la personalidad}

Al igual que la vigente Constitución Española, la GG no se refiere de manera explícita a ninguna de las formas de eutanasia o al suicidio asistido. Ello obligó al BVerfG a «concretizar (sic)» ${ }^{65}$ el contenido del derecho al libre desarrollo de la personalidad a fin de ofrecer una respuesta constitucionalmente adecuada a la problemática planteada ${ }^{66}$. Aun sin negar la necesidad de determinar si una ley infringe el ámbito de protección de un derecho, algunos especialistas han postulado un «giro desde la interpretación hacia la justificación» que debe la «operatividad de la gran mayoría de los casos de derechos humanos o constitucionales al test de proporcionalidad»: en las democracias liberales contemporáneas, los argumentos relacionados con el texto legal, la historia o el precedente jugarían un rol «relativamente modesto» ${ }^{67}$. Frente a esta tesis, Víctor Ferreres ha sostenido recientemente que los «asuntos normativos difíciles que los jueces deben tratar cuando resuelven casos son de algún modo 'externos' a los mecanismos del principio de proporcionalidad ${ }^{68}$. Un buen ejemplo de esta «externalidad» lo ofrece el célebre voto particular que Dieter Grimm formuló

64 Vid. BVerfGE de 26 de febrero de 2020, nn. mm. 69 y s., 72, 78 y 86.

65 HESSE, K. (2012). Escritos de Derechos Constitucional. Madrid: Fundación Coloquio Jurídico Europeo / Centro de Estudios Políticos y Constitucionales, pp. 63 y ss.

66 Como es sabido, con este característico modus operandi de la dogmática constitucional de posguerra se han mostrado muy críticos autores como FORSTHOFF, E. (1964). «Die Umbildung des Verfassungsgesetzes». En Rechtsstaat im Wandel. Verfassungsrechtliche Aufsätze 1950-1964. Kohlhammer Verlag: Stuttgart, pp. 154 y ss.; o BÖCKENFÖRDE, E.-W. (1993). Escritos de derechos fundamentales. Baden-Baden: Nomos Verlagsgesellschaft, pp. 31 y ss., por citar solo algunos nombres.

${ }^{67}$ KUMM, M. «The Idea of Socratic Contestation...», op. cit., p. 144. Las tesis de ALEXY, R. «Los derechos fundamentales y el principio...», op. cit., pp. 23-29, se inscriben en la misma línea, sin perjuicio de su postura se vea necesariamente matizada por lo dicho supra, p. 308, n. 62.

68 FERRERES COMELLA, V. «Beyond the principle of proportionality», op. cit., p. 231. Este autor ha señalado en el trabajo citado las cuestiones que demandan una teoría sustantiva de los derechos fundamentales: la fijación de los límites de la ponderación (ibid., p. 238), la especificación de las condiciones a satisfacer por los derechos de terceros para que justifiquen el limitar los propios (ibid., p. 
hace más de 30 años ya a la BVerfGE 80,137, más conocida como «Reiten im Wal$d e »{ }^{69}$. Como se recordará, para el magistrado discrepante:

Los derechos fundamentales se diferencian de la multitud de restantes derechos en que protegen la integridad, la autonomía y la comunicación del individuo en sus relaciones básicas. Precisamente a causa de este fundamental significado de su objeto de protección para un orden fundado sobre la dignidad humana, se los destaca del montón de derechos y se los dota de una garantía incrementada frente a los poderes públicos, especialmente el legislador. Las concepciones sobre lo que concretamente pueda ameritar la protección incrementada de los derechos fundamentales variará con las circunstancias históricas; sin embargo, la finalidad de los derechos fundamentales no es ni histórica ni funcionalmente la de colocar bajo su particular protección cada actividad humana imaginable (BVerfGE 80, 137 [n. m. 99]).

A mi juicio, este planteamiento informa claramente la sentencia del BVerfG del pasado 26 de febrero. Conforme a la jurisprudencia consolidada del alto tribunal alemán, el contenido y el alcance del ámbito de protección del derecho al libre desarrollo de la personalidad se encuentra concluyentemente circunscrito por la dignidad humana (art. 1.1 GG) ${ }^{70}$. Esta consiste en que se reconozca en todo momento al ser humano como personalidad responsable, garantizando de tal manera las condiciones fundamentales para que el individuo pueda encontrar, desarrollar, y preservar su identidad y su individualidad ${ }^{71}$. La dignidad humana, por lo tanto, contribuye a que

241), la determinación del peso abstracto de los derechos en pugna (ibid., p. 243) o la resolución de los problemas de eficacia horizontal de los derechos (ibid., p. 246).

69 La remisión resulta especialmente oportuna, toda vez que en dicho caso el BVerfG también debió pronunciarse en relación con el derecho al libre desarrollo de la personalidad.

70 «La dignidad humana es inviolable. Respetarla y protegerla es obligación de todo poder público». La conexión del derecho al libre desarrollo de la personalidad (art. 2.1 GG) con el art. 1.1 GG ha servido en otras ocasiones para proteger frente a situaciones tan dispares como falsas inscripciones en asociaciones [BVerfGE 99, 185 (193)], una excesiva exposición pública por culpa de reporteros gráficos [BVerfGE 101, 361 (380)], la utilización de equipos de audición que permiten a un tercero escuchar una conversación de los titulares del derecho [BVerfGE 106, 28 (39)], vulneraciones de la autodeterminación informativa [BVerfGE 118, 168 (183)], las amenazas para la confidencialidad e integridad de los sistemas técnicos de información [BVerfGE 120, 274 (303)] o la adjudicación de una identidad sexual necesariamente masculina o femenina [BVerfGE 147, 1 (19)]. Vid, para más detalles, STARCK, C. «Artikel 2 Absatz 2», op. cit., pp. 178-252; o SCHWABE, J. (2009). Jurisprudencia del Tribunal Constitucional Federal Alemán. Extractos de las sentencias más relevantes compiladas por Jürgen Schwabe. Berlin: Konrad Adenauer Stiftung, pp. 56-113. Para REY MARTÍNEZ, F. Eutanasia y derechos fundamentales, op. cit., pp. 82, la CE, «tan detallista en relación con los derechos fundamentales, no contiene, sin embargo, una cláusula general que, como la de privacy o la de proceso debido en Estados Unidos o la de dignidad en Alemania, por ejemplo, como auténticos derechos fundamentales permitan una interpretación evolutiva que ampare ciertas conductas no protegidas en el enunciado de la Constitución». Como se detallará en lo que sigue, el BVerfG no articula propiamente su construcción en torno a la dignidad humana como derecho fundamental, sino como principio fundamental del orden constitucional por medio del cual concretar el ámbito de protección «no concluyentemente circunscrito» de otro derecho fundamental: el libre desarrollo de la personalidad.

71 BVerfGE de 26 de febrero de 2020, n. m. 207. 
el ser humano no se vuelva «un simple objeto, no sólo de las circunstancias y del desarrollo social, sino también del derecho, en la medida en que debe adherirse a éste sin que se tomen en cuenta sus intereses ${ }^{72}$. Semejante garantía prohíbe empujar a una persona —al impedirle tomar determinadas decisiones de la máxima «relevancia existencial»— hacia formas de vida que estén en contradicción con su imagen y comprensión de sí misma. Esta prohibición de obligar a una persona a vivir de un modo que esté en contradicción con su imagen y comprensión se manifiesta, entre otros, a través del «derecho a una muerte autodeterminada» ${ }^{73}$. Este faculta a su titular no sólo para rechazar voluntariamente «medidas de conservación de la vida», sino para quitarse la vida «por propia mano» ${ }^{74}$, de tal modo que incluye también un «derecho al suicidio (Recht auf Selbsttötung)».

El ejercicio de esta facultad no está restringido, en opinión del BVerfG, a determinadas edades o fases de una enfermedad, puesto que ello implicaría una valoración de los motivos de la persona resuelta a morir y una "predeterminación material (inhaltliche Vorbestimmung)» ajena al pensamiento liberal de la GG:

El enraizamiento del derecho a una muerte autodeterminada en la garantía de la dignidad humana del art. 1.1 GG implica precisamente que la decisión, tomada bajo responsabilidad propia, sobre el fin de la vida de uno o una misma no necesita ninguna motivación o justificación adicionales. Determinante resulta la voluntad del titular del derecho fundamental, que se sustrae a una valoración a través de representaciones generales de valores, mandamientos religiosos, modelos sociales para la relación con la vida y la muerte o consideraciones de racionalidad objetiva ${ }^{75}$.

De esta forma, el BVerfG apuntaló el derecho a una muerte autodeterminada a través de un principio de neutralidad del Estado hacia las concepciones de vida que vale la pena vivir ${ }^{76}$. El derecho a una muerte autodeterminada (o las manifestaciones del mismo, como el derecho al suicidio) no podría(n) ser negado(s) alegando que el suicida atenta contra su dignidad (art. 1.1 GG) al renunciar al presupuesto de su autodeterminación y de su condición de sujeto: la vida. Para el BVerfG, la decisión de suicidarse

72 SCHWABE, J. Jurisprudencia del Tribunal..., op. cit., p. 54.

73 Vid., en el mismo sentido, ROXIN, C. «Die geschäftsmäßige Förderung...», op. cit., p. 186, para quien el derecho a una muerte autodeterminada gozaría en la República Federal de Alemania de un amplio reconocimiento jurisprudencial y doctrinal.

74 BVerfGE de 26 de febrero de 2020, n. m. 209.

75 BVerfGE de 26 de febrero de 2020, n. m. 210. La conexión entre dignidad y autonomía ha sido subrayada por DWORKIN, R. (1994). El dominio de la vida. Una discusión acerca del aborto, la eutanasia y la libertad individual. Barcelona: Ariel, pp. 313 y s., para quien «insistimos en la libertad porque valoramos la dignidad». Este autor ubica en el centro de dicha conexión «el derecho a ejercer la libertad de conciencia» que el BVerfG no llega a utilizar (cuando menos explícitamente) en su construcción. En Alemania, ROXIN, C. «Die geschäftsmäßige Förderung...», op. cit., p. 186, ha sido uno de los autores que más claramente ha vinculado la problemática aquí tratada con la libertad de conciencia (Glaubensfreibeit) reconocida en el art. 4.1 GG.

76 MONTALVO JÄÄSKELÄINEN, F. y SÁNCHEZ BARROSO, B. «La regulación de la eutanasia y el suicidio asistido...», op. cit., p. 194. 
constituye, aunque sea la última, una expresión de dignidad humana ${ }^{77}$. El individuo sólo es reconocido como sujeto cuando puede determinar su propia existencia de acuerdo con pautas autoimpuestas. Como ha explicado Reimer, el derecho a la vida no puede justificar una absoluta prohibición estatal de la ayuda a morir ${ }^{78}$.

Dado que el libre desarrollo de la personalidad ha sido constitucionalmente garantizado en el «intercambio con terceros» que, por su parte, actúan igualmente en libertad, a este derecho fundamental también pertenece, en opinión del BVerfG, la posibilidad de acudir a otras personas para recabar su apoyo y/o aceptar el auxilio por ellas ofrecido en el marco de su correspondiente libertad. Ello es igualmente aplicable a aquellas que desean poner fin por sí mismas a su propia vida ${ }^{79}$; de cualquier otro modo, el derecho individual al suicidio podría resultar vaciado. El BVerfG se sirvió, como se ve, de la tesis de la «conexión funcional» entre las diferentes conductas de los implicados en un suicidio asistido para concluir la delimitación del ámbito de protección del derecho. Dado que la protección de los derechos fundamentales de unos sería requisito para el ejercicio de un derecho fundamental por parte de otros, la garantía del derecho al suicidio también exige una protección amplia de la actuación del que ayuda a quitarse la vida. Sólo si dos personas pueden ejercer sus derechos fundamentales en aras de una meta común - en este caso la materialización de un suicidio asistido-, puede resultar efectiva la protección constitucional de la muerte autodeterminada ${ }^{80}$.

\subsection{Los límites del derecho al libre desarrollo de la personalidad}

$\mathrm{Al}$ igual que ocurre con los restantes derechos fundamentales enunciados en la GG, el ámbito abstractamente protegido por el derecho al libre desarrollo de la personalidad puede ser acortado o «restringido» ${ }^{81}$ por el legislador en aras de intereses generales o de derechos de terceras personas. Para ser constitucionalmente legítima, cualquier restricción de un derecho debe respetar las exigencias impuestas por el principio de proporcionalidad y, aun haciéndolo, en ningún caso puede violar el contenido esencial al que se refiere el art. $19.2 \mathrm{GG}^{82}$. Como es sabido, el control sobre las restricciones legislativas de un derecho ha sido históricamente ejercido por el BVerfG con una intensidad variable, dando lugar a una «teoría de los niveles (Stufen-

77 BVerfGE de 26 de febrero de 2020, n. m. 211.

78 REIMER, E. (2015). «Suizidbeihilfe: Der verfassungsrechtliche Rahmen bundesgesetzlicher Regelungen». Zeitschrift für Lebensrecht (ZfL), vol. 24, núm. 3, p. 73. Cfr. infra, pp. 25 y s.

79 BVerfGE de 26 de febrero de 2020, n. m. 213.

80 BVerfGE de 26 de febrero de 2020, n. m. 331.

81 ALEXY, R. Teoría de los derechos fundamentales, op. cit., pp. 239-256.

82 MAYER, M. (2005). Untermaß, Übermaß und Wesensgehaltgarantie. Die Bedeutung staatlicher Schutzpflichten für den Gestaltungsspielraum des Gesetzgebers im Grundrechtsbereich. Baden-Baden: Nomos, pp. 173-179. 
theorie) ${ }^{83}$ que también fue aplicaba en la sentencia aquí examinada. La claridad del pasaje amerita la referencia literal:

La evaluación y pronóstico de los peligros que amenazan al individuo o a la generalidad debe acreditar, en la comprobación constitucional, un fundamento lo suficientemente seguro [...]. El control constitucional puede llegar desde el mero control de evidencia o plausibilidad a un control material intensivo, dependiendo de la naturaleza del ámbito en cuestión, la relevancia de los bienes jurídicos en juego y las posibilidades del legislador de formarse un juicio lo suficientemente seguro [...].

Cuando, como aquí, esté en cuestión una injerencia severa en un derecho fundamental de alto rango, las incertidumbres en la valoración de los hechos no deben operar en detrimento del titular del derecho fundamental $[\ldots]^{84}$.

De este modo, el alto tribunal alemán allanaba el terreno para el más intenso control de la obra del legislador democrático tolerado por la debida «corrección funcional» ${ }^{85}$ que debe informar su actividad. Si el legislador tiene la obligación de justificar de una forma más sólida las injerencias sobre el derecho al libre desarrollo de la personalidad que las efectuadas sobre la libertad general de acción, el deber de justificación alcanza su mayor intensidad cuando el contenido garantizado del derecho revela una conexión específica con la dignidad humana ${ }^{86}$. Esta singular construcción jurisprudencial evocará para muchos una idea de «democracia vigilada, en la que el poder de control de la mayoría, el denominado poder contramayoritario, el Tribunal Constitucional Federal, vendrá a asumir un papel estelar» ${ }^{87}$. En el contexto de «sano

83 SCHUPPERT, G. F. (1980). Funktionell-rechtliche Grenzen der Verfassungsinterpretation. Regensburg: Athenäum, p. 2. La primera manifestación de esta teoría se encuentra en la conocida Apotheken-Urteil de 11 de junio de 1958 (BVerfGE 7, 377 [nn. mm. 77 y ss.]), aunque su definición más acabada no llegó hasta la Mitbestimmung-Urteil de 4 de mayo de 1976 (BVerfGE 50, 290 [n. m. 131]).

84 BVerfGE de 26 de febrero de 2020, nn. mm. 237 y s.

85 HESSE, K. Escritos de Derechos Constitucional, op. cit., pp. 68 y s.

86 Para justificar esta afirmación, el BVerfG aclaró que el favorecimiento comercial del suicidio no se basaba únicamente en la relación entre la persona resuelta a quitarse la vida y aquella dispuesta a ayudarla, sino que podía implicar considerables abusos y otros riesgos para la autodeterminación de terceros (BVerfGE de 26 de febrero de 2020, n. m. 222). Por esta razón, la aplicación del principio de proporcionalidad se movía entre dos polos representados por el derecho a quitarse la vida, por un lado, y el deber del Estado de proteger la vida y la autonomía personal, por otro. El considerable margen de evaluación, valoración y configuración otorgado al legislador para disipar los influjos o presiones externas sobre la persona resuelta a suicidarse no lo exonera del deber de considerar adecuadamente factores como la idiosincrasia del ámbito jurídico en cuestión, las posibilidades de formarse un juicio lo suficientemente seguro sobre la futura repercusión de la norma, y la relevancia de los bienes jurídicos afectados: «[El legislador] debe considerar adecuadamente el conflicto entre las dimensiones de libertad y protección del derecho fundamental» (BVerfGE de 26 de febrero de 2020, n. m. 225). Vid., en relación con los «riesgos de abuso» aludidos, SUNSTEIN, C. R. (1997). «The right to die». The Yale Law Journal, vol. 106, núm. 4, pp. 1.123-1.163; o REY MARTÍNEZ, F. Eutanasia y derechos fundamentales, op. cit., pp. 170-180.

87 MONTALVO JÄÄSKELÄINEN, F. y SÁNCHEZ BARROSO, B. «La regulación de la eutanasia y el suicidio asistido...», op. cit., p. 178. 
escepticismo» en relación con la «juristocracia» ${ }^{88}$ al que se han referido recientemente Goldoni y Wilkinson, este papel sólo puede consistir en el «filtrado» de las razones que son pertinentes para el caso y la comprobación de su capacidad legitimadora de la actuación de los poderes públicos ${ }^{89}$. Ese es, a mi entender, el sentido en que deben ser interpretadas las palabras del $\mathrm{BVerfG}^{90}$.

\subsubsection{Los requisitos justificativos de la injerencia (I): su legítima finalidad, su adecuación y su necesidad}

Al objeto de valorar la constitucionalidad de la injerencia en los derechos fundamentales de los recurrentes, el BVerfG aplicó el principio de proporcionalidad en cuatro etapas sucesivas: en primer lugar, verificó la legitimidad de la finalidad perseguida con la injerencia; en segundo lugar, comprobó la idoneidad de la misma para alcanzar dicha finalidad; en tercer lugar, examinó la necesidad de la injerencia legislativa; y, en cuarto lugar, valoró su adecuación o proporcionalidad en sentido estricto. Como se verá, el celo del BVerfG terminaría otorgando más protagonismo a unas etapas que a otras, aunque tampoco conviene dejarse engañar por los rótulos escogidos por el alto tribunal alemán: así, p. ej., una parte del examen de la legítima finalidad regulatoria de la norma — en concreto, aquel dedicado al «pronóstico del peligro (Gefabrensprognose)» ${ }^{91}$ — constituye en rigor un implícito análisis de la idoneidad de la medida. Sin perjuicio de estas leves alteraciones, el control de la proporcionalidad efectuado no conllevó novedad alguna desde un punto de vista metodológico ${ }^{92}$.

Tal y como se puso de manifiesto en el procedimiento parlamentario, el legislador alemán había tratado de poner coto a la ayuda al suicidio ofrecida comercialmente con la intención de proteger la autodeterminación personal y el derecho fundamental a la vida ${ }^{93}$. Este objetivo no sólo representaba una finalidad constitucionalmente

88 HIRSCHL, R. (2004). Towards Juristocracy: The Origins and Consequences of the New Constitutionalism. Boston, Massachusetts: Harvard University Press.

89 GOLDONI, M. y WILKINSON, M. A. (2020). «La constitución material». Revista de Estudios Políticos, núm. 187, p. 16. Disponible en: https://doi.org/10.18042/cepc/rep.187.01.

90 En este caso, parece que el BVerfG habría tratado de evitar la ausencia de un compromiso legislativo serio con las «realidades sobre el terreno (realities on the ground)» (KUMM, M. «The Idea of Socratic Contestation...», op. cit., p. 160) a las que se debía aplicar la ley. Vid. infra, p. 317. La cuestión, con todo, dista mucho de estar resuelta, por lo que habrá que esperar ulteriores posicionamientos a este respecto. Entre nosotros sigue siendo indispensable en esta materia la referencia al trabajo de FERRERES COMELLA, V. (2007). Justicia constitucional y democracia. $2^{\mathrm{a}}$ ed. Madrid: CEPC.

91 BVerfGE de 26 de febrero de 2020, nn. mm. 236-259.

92 ALEXY, R. «Los derechos fundamentales y el principio...», op. cit., pp. 13-19.

93 BTDrucks 18/5373, p. 2 y s. «Habida cuenta de la irreversibilidad de una decisión suicidio, la relevancia de la vida como más alto valor dentro del orden constitucional [...] manda contrarrestar los suicidios que no estén basados en una autodeterminación libre y la responsabilidad propia. El Estado debe precaverse de que la decisión de proceder a un suicidio asistido se base efectivamente en una voluntad libre. El legislador persigue, por consiguiente, una finalidad legítima cuando se opone a peligros para 
legítima, sino que también satisfacía la «obligación estatal de protección» ${ }^{94}$ emanada de los derechos fundamentales mencionados. La persecución de una finalidad constitucionalmente legítima no era una cuestión baladí, toda vez que, por ejemplo, una prohibición de la eutanasia comercial con el solo propósito de reducir el número de suicidios asistidos sería tan inadmisible como la reprobación o estigmatización sociales de la decisión consciente y deseada (del titular del derecho fundamental) de suicidarse con el auxilio de terceros ${ }^{95}$.

El BVerfG, con todo, no se contentó con esta modesta comprobación. En ejercicio del control material intensivo anteriormente aludido, el alto tribunal alemán valoró adicionalmente el «pronóstico de peligro (Gefabrenprognose)» efectuado por el legislador. En opinión del BVerfG, el Gefahrenprognose legislativo superaba el examen constitucional porque se orientaba por una valoración «apropiada y defendible» de la información disponible y las posibilidades cognoscitivas ${ }^{96}$. El hecho de que, conforme al actual estado de la ciencia, no exista una prueba concluyente de la eficacia de las presiones sociales ejercidas por la ayuda comercial a morir sobre personas ancianas o enfermas, no impediría que el legislador pueda ver en dicha ayuda una amenaza para la autodeterminación. Este peligro podía darse en especial en relación con personas mayores y enfermas, y ejercer - tal y como permitían entrever los datos de Suiza, los Países Bajos, Bélgica u Oregón — una presión social, económica y familiar amenazadora de la autonomía personal constitucionalmente garantizada ${ }^{97}$.

la libre formación de la voluntad y la libertad volitiva como presupuestos de la autodeterminación de la propia vida» (BVerfGE de 26 de febrero de 2020, n. m. 232 [énfasis añadido]). Puede verse una exposición de los aludidos peligros para la libre formación de la voluntad en SUNSTEIN, C. R. «The right to die», op. cit., pp. 1.141-1.146; o REY MARTÍNEZ, F. Eutanasia y derechos fundamentales, op. cit., pp. $175-188$.

94 BVerfGE de 26 de febrero de 2020, nn. mm. 231-235. Vid., en relación con las obligaciones constitucionales de protección de bienes jurídicos individuales, el trabajo seminal de MURSWIEK, D. (1985). Die staatliche Verantwortung für die Risiken der Technik: verfassungsrechtlichen Grundlagen und immissionsschutzrechtlichen Ausformung. Berlin: Duncker und Humblot, pp. 88-224. Puede consultarse una síntesis de la doctrina y la jurisprudencia al respecto en MAYER, M. Unterma $\beta$, Überma $\beta$ und Wesensgehaltgarantie..., op. cit., pp. 20-74.

95 BVerfGE de 26 de febrero de 2020, n. m. 234. En nuestro país, autores como BAJO FERNÁNDEZ, M. (2005). «Disponibilidad de la propia vida». En AA. VV. Libro homenaje al Profesor G. Rodríguez Mourullo. Madrid: Thomson Reuters - Civitas, p. 1.136, han defendido, por el contrario, que nada impediría «una política criminal que trate de evitar que los seres humanos se suiciden». La ausencia de un derecho fundamental a la propia muerte (STC 120/1990, FJ 7) conlleva que el legislador no «se halle limitado en el momento de afectar cualquier libertad de los individuos [...] por el astringente principio de proporcionalidad, sino por uno más modesto, el de razonabilidad, que protege a las personas frente a la eventual arbitrariedad de los poderes públicos (art. 9.3 CE)» (REY MARTÍNEZ, F. Eutanasia y derechos fundamentales, op. cit., pp. 166).

96 BVerfGE de 26 de febrero de 2020, n. m. 238.

97 Vid. BVerfGE de 26 de febrero de 2020, nn. mm. 250-254. El alto tribunal alemán describe aquí con cierto detalle el caso de Oregón, en cuya política sanitaria existiría un mandamiento de economicidad (Wirtschaftlichkeitsgebot) «que, en casos de enfermedades terminales, excluye la asunción de los costes de determinadas terapias médicas, mientras que prevé el reembolso de los costes de un 
Habiendo constatado de una forma tan exhaustiva tanto la legitimidad de la finalidad perseguida por la medida controvertida como (indirectamente) su idoneidad para alcanzar dicho objetivo, el BVerfG todavía añadió que la regulación del § 217 StGB no veía mermada dicha idoneidad por el hecho de que la norma penal no abarcase ni a los familiares que participasen en la actividad ilícita ni a las organizaciones transfronterizas que prestasen servicios análogos en el extranjero: la decisión del legislador protegía suficientemente los bienes jurídicos amenazados, por lo que tales «vacíos» no llegaban a poner en entredicho su idoneidad ${ }^{98}$. Sin solución de continuidad, el BVerfG pasaría a valorar fugazmente la necesidad de la medida. Para el alto tribunal alemán era cuestionable que la regulación del $\S 217$ StGB fuese necesaria para lograr el legítimo deseo legislativo de protección. En concreto, el BVerfG consideró deficientes y poco convincentes los resultados empíricos acerca de la efectividad de medidas tuitivas alternativas menos incisivas que la adoptada, pero estimó que estos defectos no bastaban para considerar la norma controvertida abiertamente innecesaria y, por tanto, inconstitucional ${ }^{99}$.

\subsubsection{Los requisitos justificativos de la injerencia (II): su adecuación o proporcionalidad en sentido estricto}

Llegado el momento de valorar la adecuación o proporcionalidad en sentido estricto del $§ 217$ StGB, el BVerfG reiteró que la decisión del legislador debía ser sometida a una mayor densidad de control que la habitual debido a que la prohibición del favorecimiento comercial del suicidio suponía una injerencia muy intensa en un derecho fundamental de «relevancia existencial» ${ }^{100}$ para las personas resueltas a suicidarse, es decir, para los destinatarios mediatos de la norma. Por más que el elevado rango de los bienes jurídicos (autonomía y vida) a proteger por medio del § 217 StGB legitimase la utilización del Derecho penal por parte del legislador, la noción de persona autodeterminada y responsable subyacente a la idea de dignidad humana debía operar como punto de partida de cualquier fórmula regulatoria. Ello se traducía en un deber de mesura legislativa incompatible con el intento de hacer frente a riesgos

\footnotetext{
suicidio asistido. Estas fórmulas revelarían el peligro de que la eutanasia lato sensu y el suicidio asistido se conviertan — habida cuenta de los crecientes costes del sistema sanitario y de cuidados — en formas normales de terminación de la vida en una sociedad, estrechando así las posibilidades individuales de elección y los márgenes de decisión. Este problema se manifiesta con especial en situaciones de carencia de suministros médicos y deficiencias el sistema de cuidados, defectos que generan miedo ante la pérdida de capacidad de autodeterminación y fomentan decisiones de suicidio» (BVerfGE de 26 de febrero de 2020, n. m. 257).

98 BVerfGE de 26 de febrero de 2020, nn. mm. 260 y ss.

99 BVerfGE de 26 de febrero de 2020, n. m. 263.

100 BVerfGE de 26 de febrero de 2020, n. m. 266.
} 
para la autonomía a través de la total suspensión de la posibilidad de autodeterminación individual ${ }^{101}$.

En principio, la regulación del $\S 217$ StGB respetaba la atipicidad constitucionalmente impuesta del suicidio y del auxilio al mismo. El reproche penal se proyectaba en exclusiva sobre el favorecimiento comercial del suicidio asistido por su carácter de fenómeno especialmente amenazante para la libertad. La prohibición, con todo, no funcionaba como acto jurídico aislado, sino que, sobre el trasfondo de la situación legal preexistente a su introducción, conducía de facto a que el derecho al suicidio constitucionalmente garantizado fuese prácticamente vaciado. Ello se debía a que la libertad excluida del ámbito penal —esto es, el favorecimiento no comercial del suicidio — no bastaba para equilibrar la restricción impuesta por la prohibición de favorecer comercialmente el suicidio. El individuo no podía ser remitido a esas alternativas sin un menoscabo real de su derecho a la autodeterminación: las «opciones restantes» solamente ofrecían una perspectiva teórica, pero no fáctica de autodeterminación ${ }^{102}$. Al presumir que cabía encontrar ayuda para el suicidio al margen de las ofertas comerciales, el legislador no había tomado suficientemente en consideración la unidad del ordenamiento jurídico.

El parlamento está naturalmente facultado para vetar determinadas formas de ejercicio de un derecho fundamental, pero entonces las opciones restantes de actuación deben ser suficientes para la realización de dicho derecho ${ }^{103}$, es decir: si el ordenamiento jurídico castiga determinadas actuaciones (como el favorecimiento comercial del suicidio) especialmente amenazantes de la autonomía individual, hace falta asegurarse de que, «a pesar de la prohibición, en el caso concreto permanece realmente abierto el acceso al auxilio al suicidio libremente puesto a disposición de la persona resuelta a acabar con su propia vida» ${ }^{104}$. Sin una oferta comercial de auxilio al suicidio, el individuo resuelto a quitarse la vida depende por completo de la disposición individual de un médico a asistirlo en su propósito, cuando menos a través de la prescripción de los principios activos necesarios poner fin a la vida. A la luz de los resultados estadísticos publicados por diversas instituciones demoscópicas y biomédicas ${ }^{105}$, de semejante disposición médica individual sólo se puede partir en casos excepcionales. La concepción que los facultativos tienen de su labor y su estricto código deontológico ${ }^{106}$ resultarían fácticamente determinantes de su renuencia a prestar ayudar para suicidarse. Precisamente frente a esta circunstancia habían reaccionado, con sus ofertas, las asociaciones en pro de una muerte digna ${ }^{107}$. A la luz de las razones expuestas,

\footnotetext{
101 BVerfGE de 26 de febrero de 2020, nn. mm. 268-277.

102 BVerfGE de 26 de febrero de 2020, n. m. 280.

3 BVerfGE de 26 de febrero de 2020, n. m. 282.

4 BVerfGE de 26 de febrero de 2020, n. m. 284 (énfasis añadido).

BVerfGE de 26 de febrero de 2020, nn. mm. 285-289.

Vid. supra, p. 9, n. 28.

107 BVerfGE de 26 de febrero de 2020, nn. mm. 290-298. La mejora de la oferta de medicina paliativa y servicios residenciales tampoco resultaba adecuada para equilibrar la restricción del derecho
} 
el BVerfG concluyó que el celo tuitivo del legislador había vaciado inexcusablemente el derecho fundamental a una muerte autodeterminada de las personas resueltas a acabar con su propia vida ${ }^{108}$.

En correlación con esta valoración, el alto tribunal alemán apreció igualmente un quebrantamiento del Derecho constitucional objetivo que obligaba a otorgar el amparo también a los destinatarios directos de la norma ${ }^{109}$. El $§ 217$ StGB implicaba un «acortamiento funcional» ilícito de su derecho al libre desarrollo de la personalidad. La libertad de quitarse la vida con ayuda de terceros no sólo está a expensas, en el tipo de casos aquí tratados, de que haya en efecto terceros dispuestos ${ }^{110}$ a conferir, proporcionar o procurar una oportunidad de suicidarse: también es necesario que tales ter-

a una muerte autodeterminada que se derivaba de la prohibición de favorecer comercialmente el suicidio. Puesto que el individuo no puede ser obligado a recurrir a un tratamiento de medicina paliativa, empujarlo hacia esas alternativas menoscabaría su derecho de autodeterminación (BVerfGE de 26 de febrero de 2020, nn. mm. 298 y s.). Finalmente, la disponibilidad de ofertas de auxilio para el suicidio en el extranjero tampoco sería adecuada para compensar la restricción impuesta por el $§ 217$ StGB. El individuo debe ver reconocido y protegido su derecho al suicidio en el interior del ordenamiento jurídico (BVerfGE de 26 de febrero de 2020, n. m. 300).

108 BVerfGE de 26 de febrero de 2020, n. m. 301. Compárese esta conclusión del BVerfG con la afirmación del Tribunal Constitucional español de acuerdo con la cual «se rebasa o se desconoce el contenido esencial cuando el derecho queda sometido a limitaciones que lo hacen impracticable, lo dificultan más allá de lo razonable o lo despojan de la necesaria protección» (STC 11/1981, FJ 8). El claro paralelismo confirmaría, como en su día apuntó GAVARA DE CARA, J. C. (1994). Derechos fundamentales y desarrollo legislativo. La garantía del contenido esencial de los derechos fundamentales en la Ley Fundamental de Bonn. Madrid: Centro de Estudios Constitucionales, p. 346, que el BVerfG es proclive a determinar caso por caso el contenido esencial de cada derecho, incluso aunque, como en la resolución aquí tratada, no emplee explícitamente esta formulación. Sobre las causas de esta omisión puede consultarse HÄBERLE, P. (2003). La garantía del contenido esencial de los derechos fundamentales en la Ley Fundamental de Bonn. Una contribución a la concepción institucional de los derechos fundamentales y a la teoría de la reserva de la ley. Madrid: Dykinson, pp. 219 y s.; o MAYER, M. Untermaß, Übermaß und Wesensgehaltgarantie..., op. cit., pp. 178 y s.

109 BVerfGE de 26 de febrero de 2020, nn. mm. 330 y s.

110 Para el supremo intérprete de la GG, en el ordenamiento jurídico alemán no sólo no existe, sino que no puede existir una obligación de prestar ayuda al suicidio (BVerfGE de 26 de febrero de 2020, n. m. 342). La argumentación del BVerfG recuerda en este punto a la tesis de RUIZ MIGUEL, A. «Autonomía individual y derecho a la propia muerte», op. cit., p. 35, según la cual «[...] garantizar el derecho a la autonomía de estos pacientes, incluso aunque se considerara un derecho fundamental, no implica que todas las personas tengan un deber universal de cooperar ni que el Estado deba proveer a ese derecho mediante una prestación (34). Bastaría simplemente garantizar legalmente el permiso para que alguna persona pudiera intervenir libremente, esto es, sin ser interferida ni verse perseguida por ello. Para probar que puede haber derechos fundamentales sin deberes correlativos no hace falta alegar, como sin duda puede hacerse en este caso, que imponer aquel deber, aunque fuera sobre funcionarios concretos, podría violar gravemente la libertad de conciencia de las personas obligadas: basta pensar que hay derechos fundamentales cuya garantía se produce de manera similar, como la libertad de contraer matrimonio o de contratar, que no exigen ni especiales prestaciones estatales ni deberes correlativos ajenos». Para REY MARTÍNEZ, F. Eutanasia y derechos fundamentales, op. cit., pp. 148, por el contrario, «si se reconociera el derecho a de una persona a obtener ayuda al morir mediante suicidio asistido y/o la eutanasia, simétricamente se estaría configurando para otra persona una obligación de matar». 
ceros puedan llevar lícitamente a la práctica su disposición. De cualquier otro modo, el derecho individual al suicidio quedaría vaciado. Como ya se ha dicho, sólo si dos personas pueden desarrollar libremente su personalidad en aras de una meta común —en este caso la materialización de un suicidio asistido—, puede resultar efectiva la protección constitucional de la muerte autodeterminada ${ }^{111}$.

\section{DOS COROLARIOS A MODO DE CONCLUSIÓN}

La problemática aquí analizada revela los límites constitucionales de la regulación legislativa del ejercicio del derecho a una muerte autodeterminada en la República Federal de Alemania. En lo que sigue se extraen de lo que se lleva dicho dos corolarios: uno de orden funcional y otro de naturaleza dogmática. Ninguno de ellos será desarrollado aquí hasta sus últimas consecuencias; ambos constituyen, por así decirlo, una invitación a la reflexión y a la investigación a partir del estudio del caso alemán.

\subsection{Corrección funcional y margen de discrecionalidad del legislador}

Antes de adoptar su fallo definitivo, el BVerfG valoró en qué medida era viable llevar a cabo una interpretación conforme con la Constitución del § 217 StGB. Aunque, a su entender, no cabía efectuar semejante interpretación —ello habría contradicho frontalmente la finalidad perseguida por el legislador ${ }^{112}$ y equivalido a una «creación del Derecho originariamente judicial» incompatible con el deber de taxatividad y previsibilidad de las leyes penales (art. 103.2 GG) ${ }^{113}$ - el tribunal dejó la puerta abierta a «conceptos alternativos de regulación». En este sentido, el BVerfG aclaró que la inconstitucionalidad del $§ 217$ StGB no implicaba necesariamente que el legislador deba abstenerse por completo de una regulación del suicidio asistido. Esta deberá en todo caso restringirse escrupulosamente a la protección de la autodeterminación individual —es decir, a la protección de las personas frente a posibles abusos o manipulaciones de su voluntad-y asegurar la calidad médica y farmacológica ${ }^{114}$.

111 BVerfGE de 26 de febrero de 2020, n. m. 331.

112 BTDrucks 18/5373, pp. 3 y 18. Aquí resuenan, mutatis mutandi, las advertencias formuladas en su día por LAMBERT, E. (2010). El gobierno de los jueces y la lucha contra la legislación social en los Estados Unidos. La experiencia norteamericana del control judicial de la constitucionalidad de las leyes. Madrid: Tecnos, pp. 145-155, en relación con Derecho norteamericano. En la República Federal de Alemania se ha ocupado de esta problemática SCHUPPERT, G. F. Funktionell-rechtliche Grenzen..., op. cit., pp. 5 y s., entre otros.

113 BVerfGE de 26 de febrero de 2020, n. m. 334.

114 BVerfGE de 26 de febrero de 2020, n. m. 338. Como ha señalado ROXIN, C. «Tratamiento jurídico-penal de la eutanasia», op. cit., p. 34, ninguna regulación de la eutanasia y el suicidio asistido debería suponer un «[...] perjudicial desmantelamiento tanto de una terapia paliativa, que de todos

(C) UNED. Revista de Derecho Político

N. ${ }^{\circ} 109$, septiembre-diciembre 2020, págs. 295-325 
De la obligación estatal de proteger la autodeterminación individual se deriva para el legislador alemán una «encomienda de actuación (Handlungsauftrag)» ${ }^{115}$. A fin de cumplir con la misma, el parlamento dispone de un amplio espectro de posibilidades regulatorias del fenómeno del suicidio asistido. Este espectro engloba tanto el diseño de «mecanismos procesales de aseguramiento» de la voluntad como la prohibición de las más peligrosas formas de aparición del suicidio asistido, o la instauración de un sistema de autorizaciones «que asegure la fiabilidad de las ofertas de auxilio al suicidio» ${ }^{116}$. Disponga lo que disponga, el legislador en ningún caso podrá fiscalizar los motivos subyacentes a la decisión individual de quitarse la vida, sujetando así la decisión a algún parámetro de razonabilidad objetiva.

Ello impedirá condicionar la ayuda al suicidio a criterios materiales como la existencia de una enfermedad incurable o mortal. La situación vital del titular del derecho sólo deberá ser tomada en consideración para constatar la seriedad y durabilidad de la voluntad de acabar con su propia vida. Desde esta perspectiva, al legislador solo le corresponde el desarrollo de un concepto procesal de aseguramiento ${ }^{117}$. En consonancia con la relevancia de los bienes jurídicos en juego, esta regulación puede radicarse en el Derecho penal, pero cualquier restricción debe dejar de facto suficiente espacio para el desarrollo y la materialización del derecho constitucionalmente protegido del individuo a quitarse la vida con auxilio de terceros de acuerdo con una decisión libremente adoptada ${ }^{118}$.

\subsection{El Tribunal Constitucional Federal alemán y el derecho a la vida}

Cabría preguntarse qué razón llevó al BVerfG a no considerar específicamente el derecho a la vida (art. 2.2 GG) en la fundamentación de la resolución analizada ${ }^{119}$. El alto tribunal alemán, por ejemplo, no pondera en ningún momento este derecho con la obligación de garantizar la autodeterminación individual. ¿A qué se debe esta renuncia? A partir de los trabajos de John Rawls, Kumm ha defendido que las «concepciones comprensivas del bien» no pertenecen al tipo de razones que pueden ser invocadas en una democracia liberal para justificar restricciones de un derecho fun-

modos está atrasada en Alemania, como de importantes exigencias humanas de una muerte asistida más intensiva, porque está a disposición un camino aparentemente más sencillo». Sobre la delicada relación entre la problemática aquí tratada y los cuidados paliativos puede verse (REY MARTÍNEZ, F. Eutanasia $y$ derechos fundamentales, op. cit., pp. 176-188) o lo dicho supra, p. 20, n. 66.

115 Vid. supra, p. 19, n. 63.

116 BVerfGE de 26 de febrero de 2020, n. m. 339.

117 BVerfGE de 26 de febrero de 2020, n. m. 340.

118 ROXIN, C. «Die geschäftsmäßige Förderung...», op. cit., p. 189.

119 Entre nosotros, las heterogéneas dificultades planteadas por el derecho fundamental a la vida han sido discutidas por ARRUEGO, G. «Los confines del derecho fundamental a la vida», op. cit., pp. 114 y ss. 
damental ${ }^{120}$. A mi entender, el BVerfG no dice otra cosa al sostener que la voluntad del titular del derecho fundamental «se sustrae a una valoración a través de representaciones generales de valores, mandamientos religiosos, modelos sociales para la relación con la vida y la muerte o consideraciones de racionalidad objetiva» ${ }^{121}$. La imposibilidad de invocar tales concepciones no sólo se manifiesta en la forma del liberal principio de neutralidad del Estado respecto de las concepciones de vida que vale la pena vivir ${ }^{122}$, sino que disocia por completo el derecho a la vida del deber de vivir: del derecho a la vida no se sigue, en Alemania, una obligación de vivir ${ }^{123}$. Esta es la razón por la que los casos de suicidio no caen allí dentro del ámbito protegido por el derecho a la vida, haciendo superflua así cualquier ponderación del mismo con el derecho al libre desarrollo de la personalidad ${ }^{124}$. En Alemania, la problemática relativa al suicidio solo puede ser adecuadamente tratada sobre el trasfondo del derecho a una muerte autodeterminada.

Desde luego, frente a este planteamiento todavía cabría replicar que del mismo no se sigue necesariamente el reconocimiento de un derecho fundamental a una muer-

120 KUMM, M. «The Idea of Socratic Contestation...», op. cit., p. 160.

121 BVerfGE de 26 de febrero de 2020, n. m. 210.

122 MONTALVO JÄÄSKELÄINEN, F. y SÁNCHEZ BARROSO, B. «La regulación de la eutanasia y el suicidio asistido...», op. cit., p. 194. Entre nosotros, por ejemplo, CHUECA RODRÍGUEZ, R. «El marco constitucional...», op. cit., p. 104, ha defendido que las convicciones personales sobre la vida y la muerte forman parte del contenido esencial del derecho a la libertad ideológica (art. 16 CE), por lo que «[...] a nadie pueda imponérsele una creencia - o no creencia-, de cualquier clase o naturaleza, en relación con estos temas».

123 LINDNER, J. (2013). «Verfassungswidrigkeit des — kategorischen- Verbots ärztlicher Suidzidassistenz». Neue Juristische Wochenschrift (NJW), vol. 66, núm. 3, p. 138.

$124 \mathrm{Vid}$, en relación con las tensiones entre el derecho a la vida y el «hipotético derecho a disponer de la propia vida», RUIZ MIGUEL, A. «Autonomía individual y derecho a la propia muerte», op. cit., o ARRUEGO, G. «Los confines del derecho fundamental a la vida», op. cit., entre otros. En mi opinión, con todo, el conflicto no se da en tales casos entre derechos, sino entre un derecho y un bien jurídico protegido (la vida, pero no el derecho a la vida). De acuerdo con su estructura fundamental, los «derechos a algo» (ALEXY, R. Teoría de los derechos fundamentales, op. cit., pp. 163-185) se presentan necesariamente como relaciones jurídicas del titular del derecho con otro u otros: los obligados por el derecho en tanto que destinatarios de la norma en la que se lo enuncia. Consecuentemente, no se puede hacer coincidir el titular del derecho a la vida y el destinatario de la norma que enuncia dicho derecho. Desconocer semejante consideración puede conducir, a la postre, a propugnar abiertamente que «la preservación de los derechos subjetivos está subordinada y debe servir a la garantía de la institución, que decide el punto de vista institucional y no el interés egoísta individual del [titular] subjetivo» [SCHMITT, C. (2003). «Freiheitsrechte und institutionellen Garantien der Reichsverfassung (1931)». En Verfassungsrechtliche Aufsatze aus den Jabren 1924-1954. Materialen zu einer Verfassungslebre. $4^{\mathrm{a}}$ ed. (1 $1^{\mathrm{a}}$ ed., 1958). Berlin: Duncker \& Humblot, p. 149]. Vid., a mayor abundamiento, HUBER, E. R. (1933). «Bedeutungswandel der Grundrechte». Archiv des öffentlichen Rechts (AöR), núm. 23, pp. 1-98. Esto podría ser lo que, entre nosotros, denuncia ARRUEGO, G. «La naturaleza constitucional de la asistencia...», op. cit., p. 76, al afirmar que «uno de los rasgos principales y más preocupantes de la doctrina elaborada por el Tribunal Constitucional acerca del contenido y significado de los derechos fundamentales a la vida y a la integridad física y moral es su excesivo apego a un discurso de marcado carácter objetivo proclive a razonar a partir de bienes y valores».

(C) UNED. Revista de Derecho Politico

N. ${ }^{\circ} 109$, septiembre-diciembre 2020, págs. 295-325 
te autodeterminada y que, justamente por eso, en otros ordenamientos jurídicos (como el español) se ha definido el suicidio simplemente como una conducta «ajurídica», un «espacio libre de regulación» o una «conducta no prohibida» ${ }^{125}$. Esta afirmación no puede ser desmentida, pero suscita dos reparos importantes. En primer lugar, nada de lo dicho impide que en esos otros ordenamientos jurídicos se construya un «espacio iusfundamental de autodeterminación personal» ${ }^{126}$ a partir de otros derechos fundamentales. En contra de lo que a veces se cree, tal cosa no supondría automáticamente la aparición de una obligación jurídica de los poderes públicos de poner fin a la vida del que lo solicite ${ }^{127}$. En segundo lugar, la falta de reconocimiento de un derecho fundamental tiene como consecuencia inevitable que el legislador disponga de un muy amplio margen de configuración de lo que ha sido caracterizado como una simple «manifestación del agere licere» (STC 120/1990, FJ 7). La cuestión es, entonces: $¿$ Hay buenos motivos para exigir del legislador menos rigor cuando regula las decisiones sobre el final de la vida que cuando se ocupa, por ejemplo, del derecho al honor, a la intimidad personal y familiar y a la propia imagen?

Las consideraciones precedentes arrojan una nueva luz sobre el trasfondo constitucional de la tradicional distinción alemana entre formas de actuación impunes y castigadas en el contexto de decisiones sobre el final de la propia vida. Como se recordará, el BVerfG excluyó a limine del ámbito protegido por el art. 2.1 GG los supuestos de eutanasia activa directa: además de facultar a su titular para rechazar voluntariamente «medidas de conservación de la vida» o tratamientos médicos, el derecho a una muerte autodeterminada también abarca el acto de quitarse la vida «por propia mano», mas no el homicidio consensuado u homicidio a petición. Se podría pensar que el alto tribunal no hizo aquí otra cosa que constitucionalizar una tradición cen-

125 REY MARTÍNEZ, F. Eutanasia y derechos fundamentales, op. cit., p. 85. La jurisprudencia del Tribunal Constitucional español en relación con las decisiones sobre el final de la propia vida se reduce a consideraciones sobre el suicidio formuladas en el contexto de huelgas de hambre de internos penitenciarios. El alto tribunal español nunca llegó a pronunciarse sobre el reconocimiento del derecho a una muerte digna solicitado por Ramón Sampedro, ya que el proceso de amparo se extinguió por el fallecimiento del demandante (ATC 242/1998, de 11 de noviembre). Un fallo desestimatorio era en todo caso previsible [PÉREZ-MANZANO, M. y TOMÁS-VALIENTE LANUZA, C. (2019). «Artículo 15». En RODRÍGUEZ-PIÑERO Y BRAVO-FERRER, M. y CASAS BAAMONDE, M. E. (dirs.), PÉREZ MANZANO, M. e BORRAJO INIESTA, I. (coords.), ARNALDO ALCUBILLA, E. y REMÓN PEÑALVER, J. (eds. lit.). Comentarios a la Constitución española. Vol. 1, Tomo 1. Madrid: Boletín Oficial del Estado / Tribunal Constitucional / Wolters Kluwer, Ministerio de Justicia, p. 382], por más que el Tribunal Constitucional introdujese un «factor desequilibrante al aceptar la alegación del propio demandante sobre el contenido de su «derecho a una muerte digna» como un derecho absolutamente personalísimo» (RUIZ MIGUEL, A. «Autonomía individual y derecho a la propia muerte», op. cit., p. 27). Vid., en este último sentido, ARRUEGO, G. «La naturaleza constitucional de la asistencia...», $o p$. cit., p. 60, y, en uno opuesto, REY MARTÍNEZ, F. Eutanasia y derechos fundamentales, op. cit., pp. 87.

126 ARRUEGO, G. «La naturaleza constitucional de la asistencia...», op. cit., p. 60.

127 REIMER, E. «Suizidbeihilfe: Der verfassungsrechtliche Rahmen...», op. cit., p. 69. Vid. supra, p. 23, n. 79 . 
tenaria ${ }^{128}$ en el país — ni la instigación ni la ayuda al suicidio se castigan allí desde la entrada en vigor del código penal del imperio, en $1872^{129}$ — o reflejar consideraciones generales de dogmática penal ${ }^{130}$. Sin embargo, hay también buenas razones de índole sistemática para justificar la distinción.

El derecho a una muerte autodeterminada debe garantizar que la persona inicialmente resuelta a morir pueda llevar a cabo su propósito, pero también cambiar de parecer incluso en el último instante, y esta posibilidad solamente puede ser preservada si es el titular del derecho el que cuenta en todo momento con el dominio sobre la acción que irremediablemente pone fin a su vida. Naturalmente, este criterio no es infalible ni resuelve todos los problemas ${ }^{131}$, pero su consonancia con la «razón pública» ${ }^{132}$ parece difícilmente cuestionable. Al abordar cuestiones relacionadas con la eutanasia y/o el suicidio asistido a partir del derecho a una muerte autodeterminada, los poderes públicos alemanes no renuncian a una modulación de las condiciones de ejercicio del derecho en atención a las amenazas para la propia autonomía individual y los derechos de terceros u otros bienes jurídicos protegidos ${ }^{133}$. En función de los peligros que se quieran contrarrestar, el derecho a una muerte autodeterminada se

128 BVerfGE de 26 de febrero de 2020, n. m. 17. Semejante influencia de la tradición jurídica evocaría inevitablemente la conocida referencia de Schmitt a las «garantías (legal-)constitucionales de institutos jurídicos en el sentido de relaciones jurídicas y complejos normativos típicos y tradicionalmente existentes» (SCHMITT, C. «Freiheitsrechte und institutionellen Garantien...», op. cit., p. 164).

129 JARVERS, K. «La fattispecie tedesca...», op. cit., p. 53.

130 Según MONTALVO JÄÄSKELÄINEN, F. y SÁNCHEZ BARROSO, B. «La regulación de la eutanasia y el suicidio asistido...», op. cit., p. 189, «[...] siendo el suicidio una conducta atípica, se ha preferido mantener la atipicidad de la participación en el suicidio ajeno y respetar así estrictamente el principio de accesoriedad en la participación penal».

131 Como ha explicado JARVERS, K. «La fattispecie tedesca...», op. cit., p. 55, «en el caso específico puede ser difícil establecer los límites. En cualquier caso, tras la última contribución del tercero antes de la última etapa, el suicida debe poder decidir libremente si vivir o morir. De otra forma, no se trata de suicidio». A mi entender, la reconstrucción efectuada no se opondría a la tesis básica que entre nosotros ha sostenido RUIZ MIGUEL, A. «Autonomía individual y derecho a la propia muerte», op. cit., p. 35, según la cual para «[...] garantizar el núcleo básico de la autonomía de los casos citados sería necesario despenalizar la cooperación en la muerte de la persona afectada y, cuando esa cooperación no sea suficiente por las circunstancias del paciente, también la producción directa de su muerte». Indudablemente, una aproximación de este calibre obligaría a refinar la regulación penal de las «decisiones de vida o muerte bajo condiciones estrechamente definidas» (SUNSTEIN, C. R. «The right to die», op. cit., pp. 1.136 y s.) o de lo que en España se conoce como «enfermedades trágicas: las incapacitantes (ej., la tetraplejia), las neurodegenerativas en estados avanzados (ej., la esclerosis lateral amiotrófica o el Alzheimer), las terminales y los estados vegetativos irreversibles» (RUIZ MIGUEL, A. «Autonomía individual y derecho a la propia muerte», op. cit., p. 13). Sin duda, el legislador es el poder público en la mejor posición institucional (FERRERES COMELLA, V. Justicia constitucional y democracia, op. cit., p. 22) para tomar una decisión sobre estos extremos.

132 KUMM, M. «The Idea of Socratic Contestation...», op. cit., p. 150.

133 En Alemania, esta modulación ha correspondido en buena medida a la jurisprudencia, por lo que «no se ha considerado necesaria una intervención del legislador» (FUCHS, M. y HÖNINGS, L. Sterbebilfe und Selbstbestimmtes Sterben..., op. cit., 34).

(C) UNED. Revista de Derecho Politico

N. ${ }^{\circ} 109$, septiembre-diciembre 2020, págs. 295-325 
puede ver restringido por la imposición de requisitos de atipicidad ${ }^{134}$ dependientes del estado del enfermo o, en todo caso, la implantación de mecanismos tendentes a constatar la voluntad de la persona resuelta a morir, como el $\S 1901$ a BGB ${ }^{135}$; pero tales limitaciones en ningún caso pueden atentar contra el contenido esencial del libre desarrollo de la personalidad.

Title:

Assisted suicide and free development of personality in the Federal Republic of Germany.

\section{Summary:}

1. The prohibition of commercial encouragement of suicide in the Federal Republic of Germany. 1.1. A brief reference to German criminal regulation in relation to euthanasia and assisted suicide. 1.2. The scientific controversy over $\S 217 \mathrm{StGB}$. 2. The right to a self-determined death in the Federal Republic of Germany. 2.1. The scope of protection of the right to free development of personality. 2.2. The limits of the right to free development of personality. 2.2.1. The justification for interferences (I): legitimate purpose, adequacy and necessity. 2.2.2. The justification for interferences (II): adequacy or proportionality in the strict sense. 3. Two corollaries by way of conclusion. 3.1 Functional correction and discretion of the legislator. 3.2. The Bundesverfassungsgericht and the right to life.

134 ¿Puede un médico, por ejemplo, prescribir una sustancia letal a un paciente que ha manifestado su voluntad de quitarse la vida? Según una reciente sentencia de la máxima instancia judicial alemana de la jurisdicción contencioso-administrativa, el § 5.1.6 de la Ley de Estupefacientes — «que prohíbe la prescripción de sustancias incluidas en el objeto de la Ley cuando la naturaleza o el propósito de su adquisición no es coherente con los propósitos de la norma, por ejemplo, con el de garantizar la atención médica necesaria de la población» (MONTALVO JÄÄSKELÄINEN, F. y SÁNCHEZ BARROSO, B. «La regulación de la eutanasia y el suicidio asistido...», op. cit., p. 190)— no impide que a una persona libre y seriamente resulta a suicidarse se le recete una sustancia letal en determinadas circunstancias (Sentencia del Bundesverwaltungsgericht de 2 de marzo de 2017, en el asunto 3 C 19.15, nn. mm. 23-33). En concreto, la prohibición establecida en el § 5.1.6 de la Ley de Estupefacientes se exceptúa cuando una enfermedad grave e incurable le ocasione un sufrimiento físico grave, un dolor especialmente intenso o un sufrimiento insoportable que no pueda ser suficientemente atenuado, sin que exista otra posibilidad razonable para realizar su deseo de morir (ibid., n. m. 31).

135 Vid., en este sentido, la sentencia del Bundesgerichtshof de 25 de junio de 2010, en el asunto 2 StR 454/09 (n. m. 24), o la más reciente de 17 de septiembre de 2014, en el asunto ZB 202/13 (nn. mm. 35-38). 


\begin{abstract}
:
This paper analyses the legal controversy aroused in the Federal Republic of Germany around the prohibition of commercial encouragement of suicide. In its first section, the legal framework for end-of-life decisions is briefly explained. To this end, the work emphasises the contentious criminal act in force in the country since 2015 and reflects the state of the art according to the main scientific literature in this regard. The second part analyses the recent ruling of the German Federal Constitutional Court that declares unconstitutional the above-mentioned prohibition of commercial encouragement of suicide. In particular, this section looks into the construction of a right to a self-determined death carried out by the final arbiter of the German Fundamental Law. Thirdly and lastly, the paper draws two conclusions from the prior analysis. The first one is of functional nature and, since the German Federal Constitutional Court did not exclude such a possibility, refers to the feasibility of alternative concepts of legislation. The second corollary has a dogmatic nature and consists of assessing the significant omission of the right to life in the argumentation of the German highest court.
\end{abstract}

\title{
Palabras clave:
}

dignidad humana; libre desarrollo de la personalidad; derecho a una muerte autodeterminada; favorecimiento comercial del suicidio; principio de proporcionalidad; contenido esencial.

\section{Keywords:}

human dignity; free development of personality; right to a self-determined death; commercial facilitation of suicide; proportionality principle; essence of a right. 
